\title{
ENVIRONMENTAL ABATEMENT AND INTERGENERATIONAL DISTRIBUTION
}

\author{
A. Lans Bovenberg* \\ Center for Economic Research, \\ Tilburg University, OCFEB and CEPR \\ Ben J. Heijdra* \\ University of Groningen and OCFEB
}

\begin{abstract}
This paper employs an overlapping generations model to explore the impact of public abatement on private investment and the intergenerational distribution of welfare. Whereas public abatement benefits old generations in terms of non-environmental welfare, future generations gain most in terms of environmental welfare. The overall benefits tend to be smallest for generations born at the time of the unanticipated policy shock. Public debt policy, however, can be employed to ensure that welfare gains are distributed more equally across the various generations. Such a policy implies that natural capital crowds out man-made capital.
\end{abstract}

JEL codes: $\quad$ D60, H23, H63, Q28

Keywords: overlapping generations, public environmental abatement, intergenerational welfare effects, debt policy.

September 1998

\section{Corresponding author:}

A. Lans Bovenberg

CentER, Tilburg University

P.O. Box 90153

5000 LE Tilburg

The Netherlands

Phone: +31-13-466-2912

Fax: +31-13-466-3042

Email: a.l.bovenberg@kub.nl
Ben J. Heijdra

NAKE, University of Groningen

P.O. Box 800

9700 AV Groningen

The Netherlands

Phone: +31-50-363-7303

Fax: +31-50-363-7207

Email: b.j.heijdra@eco.rug.nl

* We are grateful to D.P. Broer for helpful comments. 


\section{CONTENTS}

1. Introduction

2. The model

2.1. Households

2.2. Firms

2.3. The government

2.4. Ecology

2.5. Summary of the model

3. Raising public abatement

3.1. The macroeconomy

3.2. Factor prices

3.3. The ecology

3.4. No overlapping generations: The efficiency case for public abatement

3.5. Intergenerational welfare

3.5.1. Non-environmental welfare

3.5.2. Environmental welfare

3.5.3. Total welfare: Pareto improving reforms

3.6 Numerical illustration

4. Intergenerational redistribution policy

4.1. Compensating existing generations only

4.2. Egalitarian policy

5. Conclusions

References

Figure 1. Equilibrium and stability

Figure 2. Macroeconomic effects of public abatement

Figure 3.a. The effect of the speed of introduction on the welfare paths

Figure 3.b. The effect of the initial share of abatement on the welfare paths

Figure 3.c. The effect of the birth rate on the welfare paths

Figure 4.a. Required environmental weights and policy speed

Figure 4.b. Required environmental weights and initial abatement share

Figure 4.c. Required environmental weights and birth rate

Table 1. The model in levels

Table 2. The log-linearised model

Table 3. Welfare effects

Table 4. The efficiency and intergenerational distribution effects of public abatement. 


\section{Introduction}

In recent years, serious environmental problems have increased the interest in public policies aimed at cleaning up the natural environment. However, two objections are often raised against more public spending for environmental programs. First, more public spending may crowd out private investment, thereby harming capital accumulation. Second, the intergenerational distributional effects of the spending programs are likely to be unattractive from a political point of view: the current generations, who have the voting power, pay for the additional public spending through higher taxes but enjoy only small environmental benefits because the environment improves only gradually due to stock-flow dynamics. Indeed, one can view the additional public abatement as an investment in natural capital. The costs of these public investments are borne by the current generations while the benefits in terms of a cleaner environment accrue mainly to future generations who are not yet born at the time the investment must be implemented. ${ }^{1}$

This paper explores these two issues within the context of an overlapping-generations model. In doing so, it investigates not only the macroeconomic effects of environmental policy on saving and investment but also the implications of environmental policy for efficiency and the intergenerational distribution. Moreover, we analyze the role of public debt in reducing the intergenerational distributional effects of public abatement.

Most of the other literature on environmental policy in an overlapping-generations context (see, e.g., Howarth (1991), Howarth and Norgaard (1990, 1992), John and Pecchenino (1994), John et al. (1995), Mourmouras (1993)) employs the model developed by Diamond (1965). ${ }^{2}$ In this model, agents live for two periods only. This makes the model less suited to study transitional dynamics. We employ the overlapping-generations model popularized by Blanchard (1985) to explore the distributional effects associated with transitional dynamics. Also Marini and Scaramozzino (1995) adopt this model to explore environmental policy. Whereas they employ a social welfare function to compute optimal policies, we focus on Pareto-improving policies as well as policies that are favoured by a majority of the voting population. In this connection, we explore the role of public debt in ensuring that all generations benefit. Moreover, in contrast to Marini and Scaramozzino (1995), we investigate the transitional behaviour of the economy after tightening environmental policy.

Bovenberg and Heijdra (1998) employ a similar model to investigate the impact of a higher pollution tax. Our present paper differs from Bovenberg and Heijdra (1998) in two major respects. First, we investigate a different instrument of environmental policy, namely public abatement rather than a pollution tax on capital. Hence, whereas Bovenberg and Heijdra (1998) 
relates to the literature on capital taxation, the present paper is closely related to the literature on the macroeconomic and welfare effects of public spending. The distributional effects of public abatement appear to be rather different from the corresponding effects of pollution taxes. In particular, older generations gain rather than lose in terms of non-environmental welfare. A second major difference compared to Bovenberg and Heijdra (1998) is that we analyze public debt policies that are aimed at making all current generations equally well off.

Our paper relates to the literature on crowding out of public spending. Judd (1985) investigates the macroeconomic impacts and welfare effects of public consumption in a closed economy with a representative, infinitely-lived agent. We extend this analysis to a model with overlapping generations and public spending that has an investment character (i.e. the benefits accrue only gradually due to stock-flow dynamics). ${ }^{3}$ Moreover, by including environmental amenities and environmental quality, we can explore the interaction between man-made and natural capital and the trade-offs between non-environmental and environmental welfare.

To analytically compute the transition to a new steady state, we employ the loglinearisation techniques introduced by Judd (1982). The analytical solutions explicitly reveal how several major structural parameters affect the intergenerational welfare effects of environmental abatement. In particular, it identifies the roles of, among other things, the probability of death (which reflects the length of the planning horizon), the regeneration capacity of the environment (which determines how fast the environment converges to a new ecological equilibrium after a reduction in pollution), and the initial abatement share (which measures how ambitious environmental policy is in the initial equilibrium).

\section{The model}

\subsection{Households}

The household model builds on the work of Yaari (1965) and Blanchard (1985). A constant population of agents faces a constant probability of death. The utility functional in period $t$ of a representative agent of the generation born at time $v$ features the following form:

$$
U(v, t) \equiv \int_{t}^{\infty}\left[\log C(v, \tau)+\gamma_{E} \log E(\tau)\right] \exp [(\rho+\lambda)(t-\tau)] \mathrm{d} \tau
$$

Here, $C(v, \tau)$ denotes consumption of private commodities in period $\tau$ of an agent born at time $v$, $E(\tau)$ represents the quality of the environment in period $\tau, \rho \geq 0$ stands for the pure rate of time 
preference, $\lambda \geq 0$ is the probability of death (which corresponds to the birth rate so that the population is constant), and $\gamma_{E}$ denotes the weight in overall utility attached to environmental amenities. Utility is separable in private consumption and the quality of the environment. Accordingly, the quality of the environment does not directly affect household consumption. The logarithmic specification of utility from private consumption implies that saving behaviour is guided by a unitary intertemporal elasticity of substitution. Without leisure entering utility, labour supply is exogenously fixed.

Households face the following budget identity:

$$
\frac{\mathrm{d} A(v, \tau)}{\mathrm{d} \tau}=[r(\tau)+\lambda] A(v, \tau)+W(\tau)-T(\tau)-C(v, \tau),
$$

where $r(\tau)$ denotes the real rate of interest on financial assets, $W(\tau)$ represents the wage rate, $T(\tau)$ are net lump-sum taxes, ${ }^{4}$ and $A(v, \tau)$ stands for real financial assets owned in period $\tau$ by a household born at time $v$. The return on financial assets exceeds the rate of interest because, in the absence of bequest motives, agents conclude actuarially fair annuity contracts with life insurance companies. In particular, agents receive an annuity payment from the insurance company proportional to their financial wealth $(\lambda A(v, \tau))$ in exchange for transferring their entire estate to the insurance company upon death. Since the contracts are actuarially fair, the annuity rate equals the death rate $\lambda$.

The representative agent chooses a time profile for $C(v, \tau)$ by maximising $(2.1)$ subject to (2.2) and a transversality condition. The solution for consumption in period $t$ amounts to:

$$
C(v, t)=(\rho+\lambda)[A(v, t)+H(t)],
$$

where (age-independent) expected life-time human wealth, $H(t)$, is given by:

$$
H(t) \equiv \int_{t}^{\infty}[W(\tau)-T(\tau)] \exp \left[-\int_{t}^{\tau}[r(\mu)+\lambda] \mathrm{d} \mu\right] \mathrm{d} \tau .
$$

After-tax wages are defined as the return to human capital, i.e., $W^{N}(t) \equiv W(t)-T(t)$.

The simple demographic structure of the model allows one to analytically aggregate generations. During each unit of time, a cohort of size $\lambda L$ is born while $\lambda L$ agents pass away. The resulting constant population size $L$ is normalised to unity. Given this simple demographic structure, aggregate financial wealth, $A(t)$, is defined by $A(t) \equiv \lambda \int_{-\infty}^{t} A(v, t) \mathrm{e}^{\lambda(v-t)} \mathrm{d} v$. The aggregate values for $C(t), T(t)$, and $H(t)$ are obtained in the same fashion. This yields the following equations describing the behaviour of the aggregate household sector: 


$$
\begin{gathered}
\dot{A}(t)=r(t) A(t)+W(t)-T(t)-C(t), \\
C(t)=(\rho+\lambda)[A(t)+H(t)], \\
\dot{H}(t)=[r(t)+\lambda] H(t)-W(t)+T(t) .
\end{gathered}
$$

Equation (2.3) is the aggregate version of the household budget identity (2.2). The annuity payments, $\lambda A(v, \tau)$, at the right-hand side of (2.2) are a transfer from those who die to those who remain alive and therefore do not enter the economy-wide budget identity (2.3).

\subsection{Firms}

The production sector of the economy is perfectly competitive. The production function is Cobb-Douglas with constant returns to scale to the factors capital, $K(t)$, and labour, $L(t)$ :

$$
Y(t) \equiv F(K(t), L(t))=\gamma_{0} K(t)^{\varepsilon_{L}} L(t)^{1-\varepsilon_{L}},
$$

where $Y(t)$ denotes net ${ }^{5}$ production, $\gamma_{0}>0$, and $0<\varepsilon_{L}<1$. Firms maximise the value of the firm, $V(t)$, which is defined as follows:

$$
V(t)=\int_{t}^{\infty}\left[Y(\tau)-W(\tau) L(\tau)+\delta_{K} K(\tau)-I(\tau)\right] \exp \left[-\int_{t}^{\tau} r(\mu) \mathrm{d} \mu\right] \mathrm{d} \tau,
$$

subject to the production function and the following dynamic constraint for capital accumulation:

$$
\dot{K}(\tau)=I(\tau)-\delta_{K} K(\tau)
$$

where $\delta_{K}$ stands for the depreciation rate of capital, and $\dot{K}(\tau) \equiv \mathrm{d} K(\tau) / \mathrm{d} \tau$ denotes the rate of change in the capital stock. ${ }^{6}$ The first-order conditions for labour and capital demand imply that the marginal productivity of labour and capital equals the producer costs of these production factors:

$$
\frac{\partial Y(\tau)}{\partial L(\tau)}=W(\tau), \quad \frac{\partial Y(\tau)}{\partial K(\tau)}=r(\tau)
$$

We abstract from adjustment costs in investment. Accordingly, the value of equity corresponds to the replacement value of the capital stock, i.e. $V(t)=K(t){ }^{7}$ 


\subsection{The government}

The intergenerational welfare implications of tax policy depend on the way the government balances its budget. The periodic budget identity can be written as follows:

$$
\dot{B}(\tau)=r(\tau) B(\tau)+G(\tau)-T(\tau),
$$

where $B(\tau)$ and $G(\tau)$ stand for, respectively, outstanding government debt and public abatement spending at time $\tau$. The government can finance its spending by either issuing more debt $(\dot{B}(\tau) \equiv \mathrm{d} B(\tau) / \mathrm{d} \tau>0)$ or by levying lump-sum taxes $(T(\tau))$. The following No Ponzi Game condition ensures that the government remains solvent:

$$
\lim _{\tau \rightarrow \infty} B(\tau) \exp \left[-\int_{t}^{\tau} r(\mu) \mathrm{d} \mu\right]=0
$$

The government's intertemporal budget constraint is derived by integrating (2.8) and using the solvency condition (2.9):

$$
B(t)=\int_{t}^{\infty}[T(\tau)-G(\tau)] \exp \left[-\int_{t}^{\tau} r(\mu) \mathrm{d} \mu\right] \mathrm{d} \tau
$$

\subsection{Ecology}

The environment is modelled as a renewable resource. Its quality depends negatively on the amount of pollution that is generated in the production process. Denoting the stock of pollution at time $\tau$ by $P(\tau)$, we write the general form of the emission equation as $\dot{P}(\tau)=H(P(\tau), K(\tau), G(\tau))$. Nature features a regenerative capacity so that $\partial H / \partial P<0$. By raising production, a larger capital stock yields additional emissions, i.e., $\partial H / \partial K>0$. Finally, public abatement activities reduce emissions, so that $\partial H / \partial G<0$.

Environmental quality depends on the stock of pollution in deviation from some constant (virgin) value $\bar{P}$, i.e. $E(\tau) \equiv \bar{P}-P(\tau)$. Hence, the evolution of the environmental quality is determined by:

$$
\dot{E}(\tau)=-H(\bar{P}-E(\tau), K(\tau), G(\tau)) \equiv f(E(\tau), K(\tau), G(\tau))
$$

This ecological relationship has been loglinearized as in (T.4') in Table 2. The parameter $\alpha_{E}$ represents the adjustment speed of the environment $\left(\alpha_{E} \equiv-f_{E}>0\right)$. A high value for $\alpha_{E}$ implies that nature regenerates quickly. $\alpha_{K} \quad\left(\equiv f_{K} K / f_{E} E>0\right)$ and $\alpha_{G} \quad\left(\equiv-f_{G} Y / f_{E} E>0\right)$ measure the steady-state elasticities of environmental quality with respect to, respectively, physical capital and abatement 
spending. ${ }^{8}$

\subsection{Summary of the model}

Table 1 presents the complete model. Equations (T.1)-(T.4) represent the dynamic part of the model. Aggregate consumption evolves according the aggregate Euler equation (T.1), ${ }^{9}$ which can be written as:

$$
\begin{gathered}
\frac{\dot{C}(t)}{C(t)}=\left[F_{K}(K(t), 1)-\rho\right]-\lambda(\rho+\lambda)\left(\frac{K(t)+B(t)}{C(t)}\right) \\
=\frac{\dot{C}(v, t)}{C(v, t)}-\lambda(\rho+\lambda)\left(\frac{K(t)+B(t)}{C(t)}\right) \\
=\frac{\dot{C}(v, t)}{C(v, t)}-\lambda\left(\frac{C(t)-C(t, t)}{C(t)}\right)
\end{gathered}
$$

The first term at the right-hand sides of these equations denotes individual consumption growth, while the second term indicates how the replacement of older (and thus richer) by younger (and thus poorer) generations reduces aggregate consumption growth. The development of stocks of aggregate physical capital, government debt, and environmental quality are described by, respectively, (T.2), (T.3), and (T.4). The static part of the model is represented by equations (T.5)(T.7). (T.5) models the aggregate net production function, and the marginal productivity conditions are given by (T.6) and (T.7).

Only four fundamental parameters fully characterise the model. This minimal set consists of the probability of death, $\lambda \geq 0$, the rate of time preference, $\rho>0$, the initial steady-state share of government spending on abatement in income, $\omega_{G}$, and the net income share of labour, $\varepsilon_{L}$. Once these parameters are known, the steady-state capital-output ratio $(K / Y)$, the interest rate $(r)$, and the share of human wealth in total wealth $\left(\omega_{H} \equiv H /(H+K)\right)$ are uniquely determined. It is often useful, for ease of interpretation, to write $r=\rho+\lambda\left(1-\omega_{H}\right)$, so that we can express the model in terms of $\lambda, \rho$, $\omega_{G}$, and $r$ instead. This also shows more clearly that in the special case of infinite horizons (i.e. $\lambda=0)$ the steady-state interest rate is fixed by the discount rate.

Proposition 2.1: Assume $\omega_{G}<\varepsilon_{L}$. A stable long-run equilibrium exists to (T1)-(T7). This equilibrium is dynamically efficient. The equilibrium interest rate satisfies $\rho<r<\rho+\lambda$, and depends on the fundamental parameters according to: $\mathrm{d} r / \mathrm{d} \lambda>0,0<\mathrm{d} r / \mathrm{d} \rho<1, \mathrm{~d} r / \mathrm{d} \omega_{G}>0$, and $\mathrm{d} r / \mathrm{d} \varepsilon_{L}<0$. 
PROOF: See Bovenberg and Heijdra (1998).

To analyze the model, we log-linearise the various equations around the initial steady state. Table 2 contains the log-linearised model. ${ }^{10}$ A variable with a tilde (“ ") is generally defined as the per-unit deviation from the initial steady-state, e.g., $\tilde{X}(t) \equiv \mathrm{d} X(t) / X$. For a number of variables, we adopt the following alternative notational conventions:

$$
\tilde{G}(t) \equiv \frac{\mathrm{d} G(t)}{Y}, \quad \tilde{T}(t) \equiv \frac{\mathrm{d} T(t)}{Y}, \quad \tilde{B}(t) \equiv \frac{r \mathrm{~d} B(t)}{Y}
$$

The combination of a tilde and a dot represent the time rate of change in terms of the initial level. Proposition 2.2 summarises some results that will prove useful in the rest of the paper.

PROPOSITION 2.2: The log-linearized model features characteristic roots $r^{*}>0$ and $-h^{*}<0$. The unstable root satisfies $r^{*}>\lambda+r$ and the stable root satisfies $-h^{*}<r-(\rho+\lambda)$.

PROOF: See Bovenberg and Heijdra (1998).

Figure 1 draws the phase diagram associated with the model. With infinite horizons (i.e. $\lambda=0$ ), the $\dot{C}=0$ and $\dot{K}=0$ lines intersect in point A. The steady-state capital stock is given by $K^{K R}$, which is the Keynes-Ramsey capital stock for which the real rate of interest equals the pure rate of time preference (i.e., $r=\partial F / \partial K=\rho)$. If lives are finite $(\lambda>0)$, the $\dot{C}=0$ line is upward sloping with a vertical asymptote at $K=K^{K R}$.

The $\dot{C}=0$ and $\dot{K}=0$ lines yield a unique, saddle-point stable equilibrium (point $\mathrm{E}_{0}$ ), which defines the Blanchard-Yaari level of the capital stock, $K^{B Y}$. If $G$ is increased, the $\dot{K}=0$ line shifts down horizontally (see the dashed line in Figure 1). As a result, the equilibrium point $\mathrm{E}_{0}$ shifts down and to the left.

\section{Raising public abatement}

This section explores the effects of raising public abatement. The higher level of abatement is phased in either gradually or in an abrupt fashion. We abstract from public debt policy. In particular, the public budget is balanced at each point in time by adjusting lump-sum taxes. We normalise time so that the unanticipated policy shock occurs at time $t=0 .{ }^{11}$ The shock takes the following shape: 


$$
\tilde{G}(t)=\mathrm{A}\left(\xi_{G}, t\right) \tilde{G}
$$

where $\xi_{G}>0$ and $\mathrm{A}\left(\xi_{G}, t\right) \equiv 1-\mathrm{e}^{-\xi_{G} t}$ is a single adjustment term with $\mathrm{A}\left(\xi_{G}, 0\right)=1-\lim _{t \rightarrow \infty} \mathrm{A}\left(\xi_{G}, t\right)=0$. Furthermore, $\mathrm{dA}\left(\xi_{G}, t\right) / \mathrm{d} t \geq 0$ (See Lemma A.1 in Bovenberg and Heijdra (1998)). If $\xi_{G} \rightarrow \infty$, the shock is introduced instantaneously; announcement and implementation coincide so that anticipation effects are absent. If $\xi_{G}$ is finite, implementation occurs only gradually after announcement, which gives rise to anticipation effects.

\subsection{The macroeconomy}

The increase in public abatement is financed through higher lump-sum taxes. The higher taxes cause the value of human capital to decline. As a result of the negative wealth effect, consumption falls at impact:

$$
\tilde{C}(0)=\frac{-\xi_{G}\left[r^{*}-(r-\rho)\right] \tilde{G}}{r^{*}\left(r^{*}+\xi_{G}\right) \omega_{C}}<0 .
$$

The impact effect on private investment is ambiguous:

$$
\left(\frac{1-\varepsilon_{L}}{r}\right) \dot{\tilde{K}}(0)=-\tilde{G}(0)+\left(1-\frac{(r-\rho)}{r^{*}}\right)\left(\frac{\xi_{G}}{r^{*}+\xi_{G}}\right) \tilde{G} .
$$

If the policy is introduced abruptly $\left(\xi_{G} \rightarrow \infty\right.$, and $\left.\tilde{G}(0)=\tilde{G}\right)$, private investment declines unless the birth rate is zero (i.e. $\lambda=0$ so that $r=\rho$ ). With a fixed capital stock and hence fixed output supply in the short run, the rise in public abatement demand crowds out private investment because the short-run drop in private consumption is not sufficiently large to offset the increase in public abatement. The relatively small drop in private consumption originates in intergenerational distribution in favour of current generations (see below). These intergenerational distributional effects are absent if the birth rate is zero. In that case, therefore, private consumption declines sufficiently to offset the rise in public abatement so that private investment remains constant.

If the shock is not yet implemented at $t=0$ and thus only anticipated at that time (i.e., $\tilde{G}(0)=0$ since $\left.\xi_{G}<\infty\right)$, capital accumulation rises rather than falls initially (since $r^{*}>r+\lambda>r-\rho$ ). Intuitively, households adjust their consumption downward in anticipation of the future lump-sum taxes that will be required to finance the additional future public spending. In the short run, this leaves more room for private investment as the increase in public spending takes effect only in the future. Intuitively, short-term investment rises because, in contrast to the government, consumers 
practice consumption smoothing (see also Judd (1985)).

As times goes by, however, public abatement rises and the additional public demand starts to crowd out private investment. Eventually, the capital stock falls to a lower level than before the shock. In particular, the stock of capital follows the following time path:

$$
\tilde{K}(t)=\mathrm{A}\left(h^{*}, t\right) \tilde{K}(\infty)+\left(\frac{r\left[r-\rho+\xi_{G}\right]}{\left(1-\varepsilon_{L}\right)\left(r^{*}+\xi_{G}\right)}\right) \mathrm{T}\left(h^{*}, \xi_{G}, t\right) \tilde{G}
$$

where $\mathrm{T}\left(\alpha_{1}, \alpha_{2}, t\right)$ denotes a so-called single transition term:

$$
\mathrm{T}\left(\alpha_{1}, \alpha_{2}, t\right) \equiv \begin{array}{ll}
\frac{e^{-\alpha_{2} t}-e^{-\alpha_{1} t}}{\alpha_{1}-\alpha_{2}} & \text { for } \alpha_{1} \neq \alpha_{2} \\
t e^{-\alpha_{1} t} & \text { for } \alpha_{1}=\alpha_{2}
\end{array}
$$

and $\tilde{K}(\infty)$ stands for the long-run effect on the capital stock: ${ }^{12}$

$$
\tilde{K}(\infty)=\left[\frac{-(r-\rho)}{r \varepsilon_{L} \omega_{C}+\left(\varepsilon_{L}-\omega_{G}\right)(r-\rho)}\right] \tilde{G} \leq 0 .
$$

The first term on the right-hand side of (3.4) represents the transition path associated with a permanent unanticipated shock. The term involving the single transition term $\mathrm{T}\left(h^{*}, \xi_{G}, t\right)$ describes the modifications to the transition path due to the gradual introduction of the shock $\left(0<\xi_{G} \ll \infty\right)$. The single transition term is bell-shaped, zero at impact and in the long run, and positive during the transition (see Lemma A.2 in Bovenberg and Heijdra (1998)). It vanishes if the shock is applied abruptly (i.e. $\xi_{G} \rightarrow \infty$ ). A low value of $\xi_{G}$, in contrast, implies that the shock is applied only slowly. The associated anticipation effects give rise to a fall in private consumption in advance of the rise in public abatement. The associated crowding in of investment produces a temporary rise in the stock of private capital, which is reflected in the last term at the right-hand side of (3.4).

Equation (3.5) shows that the long-run effect of additional abatement on the capital stock is negative, unless agents are infinitely lived, in which case $\lambda=0$ and $r=\rho$. Also, long-run consumption declines as a result of the additional abatement (even if agents are infinitely lived):

$$
\tilde{C}(\infty)=\left[\frac{-\left(r-\rho+r \varepsilon_{L}\right)}{r \varepsilon_{L} \omega_{C}+\left(\varepsilon_{L}-\omega_{G}\right)(r-\rho)}\right] \tilde{G}<0 .
$$

In case of a zero birth rate, private consumption makes sufficient room for the additional public spending so that capital accumulation is not affected (compare Judd (1985)). If the birth rate is 
positive, however, private consumption does not decline sufficiently to prevent private investment from being crowded out by additional public demand. The resulting drop in private investment harms capital accumulation. The production capacity therefore declines gradually over time. Accordingly, in the long run, consumption is crowded out by more than one hundred percent.

The intertemporal reallocation of aggregate consumption away from the future towards the present originates in intergenerational redistribution. The higher lump-sum taxes amount to taxes on human capital. These taxes impose a heavier burden on younger generations than on older generations because the younger generations rely more heavily on human capital and less on financial capital to finance their consumption. More specifically, at any time $t>0$, the younger generations who were born after the policy shock (at $t=0$ ) rely more on human capital than the older generations who were already alive at $t=0$. These future, younger generations thus bear most of the burden of financing the additional public spending. The intergenerational redistribution in favour of current generations bolsters aggregate consumption in the short run, thereby harming investment. The transition path for consumption is given by:

$$
\tilde{C}(t)=\tilde{C}(0)\left[1-\mathrm{A}\left(h^{*}, t\right)\right]+\mathrm{A}\left(h^{*}, t\right) \tilde{C}(\infty)+\left(\frac{r\left[r-\rho+r \varepsilon_{L}\right]}{\left(1-\varepsilon_{L}\right)\left(r^{*}+\xi_{G}\right)}\right) \mathrm{T}\left(h^{*}, \xi_{G}, t\right) \tilde{G}
$$

The phase diagram for consumption and the capital stock, which is contained in Figure 2, illustrates the transition towards a new steady state. The IS curve represents all points for which the goods market is in equilibrium with a constant capital stock. The MKR curve stands for the modified Keynes-Ramsey rule, i.e., the steady-state aggregate Euler equation modified for the presence of overlapping generations. In terms of Figure 2, the increase in government spending shifts the IS curve down from $\mathrm{IS}_{0}$ to $\mathrm{IS}_{1}$. This causes the long-run equilibrium to shift from $\mathrm{E}_{0}$ to $\mathrm{E}_{1}$. Hence, both long-run consumption and the long-run capital stock drop. The arrows denote the dynamic forces associated with the old equilibrium $\mathrm{E}_{0}$, while SP represents the saddle path associated with the new equilibrium $\mathrm{E}_{1}$.

If the policy is introduced instantaneously $\left(\xi_{G} \rightarrow \infty\right)$, the economy jumps at time $t_{0}=0$ from $\mathrm{E}_{0}$ to $\mathrm{A}$ (described by equation (3.2)) onto the saddle path, after which gradual adjustment follows towards $\mathrm{E}_{1}$. The first term in equation (3.4) and the first two terms in (3.6) describe this path. If the policy is introduced gradually $\left(\xi_{G}\right.$ finite), anticipation effects are relevant. Heuristically, the adjustment path becomes more like that associated with a pure anticipated abrupt shock, ${ }^{13}$ i.e., first, at announcement time $t_{0}=0$, the jump from $\mathrm{E}_{0}$ to $\mathrm{B}$; second, between announcement and implementation time, gradual movement from $\mathrm{B}$ to $\mathrm{C}$ on the new saddle path according to the dynamic forces associated with the old equilibrium; and finally, after implementation, gradual 
movement along the saddle point associated with the new equilibrium from $\mathrm{C}$ to $\mathrm{E}_{1}$. The more gradually the policy is introduced (i.e., the lower is $\xi_{G}$ ), the more the actual adjustment path represents the path associated with an anticipated abrupt policy chock. Also the size of the jump from $\mathrm{E}_{0}$ to $\mathrm{B}$ is directly regulated by the value of $\xi_{G}$ (see also equation (3.2)).

Figure 2 thus confirms that, in the case of an anticipated policy shock, the adjustment of the capital stock is non-monotonic as the dynamic forces of the old equilibrium dominate immediately after the instantaneous fall in consumption due to the anticipation of a higher tax level. The dynamic forces in Figure 2 show also that the adjustment path for consumption must be monotonic. A simple application of the initial value theorem confirms this for the initial development of consumption:

$$
\dot{\tilde{C}}(0)=-\left(\frac{(r-\rho)\left[r^{*}-(r-\rho)\right]}{r^{*} \omega_{C}}\right)\left(\frac{\xi_{G}}{r^{*}+\xi_{G}}\right) \tilde{G}<0 .
$$

The intergenerational redistribution in favour of current, older generations and at the expense of future, younger generations causes consumption to fall over time. Only if a zero birth rate (which implies that $r=\rho$ ) excludes intergenerational redistribution, does not consumption decline further after an initial drop. In that latter case, consumption smoothing by a representative, infinitely lived household implies that aggregate consumption remains constant.

Proposition 3.1 shows that the (non-) monotonicity results extend to the entire adjustment paths for capital and consumption.

PROPOSITION 3.1: The solution paths for consumption and the capital stock (represented by, respectively, (3.4) and (3.6)) satisfy the following properties:

(i) The adjustment path of the capital stock cannot be monotonous unless the unanticipated policy is introduced abruptly $\left(\xi_{G} \rightarrow \infty\right)$.

(ii) After an initial drop at the time of the policy shock, aggregate consumption declines further in a monotonic fashion unless the birth rate is zero. In the latter case, consumption remains constant after the initial drop.

PROOF: See Bovenberg and Heijdra (1998).

\subsection{Factor prices}


This sub-section studies the adjustment path of earnings on physical capital (i.e. the rate of interest) and human capital (i.e., after-tax wages defined as the difference between gross wages and lump-sum taxes). Using $\tilde{r}(t) \equiv-\varepsilon_{L} \tilde{K}(t)$ and the solution for the capital stock (3.4), we arrive at the following time path of the interest rate:

$$
\tilde{r}(t)=-\varepsilon_{L} \mathrm{~A}\left(h^{*}, t\right) \tilde{K}(\infty)-\left(\frac{r \varepsilon_{L}\left[r-\rho+\xi_{G}\right]}{\left(1-\varepsilon_{L}\right)\left(r^{*}+\xi_{G}\right)}\right) \mathrm{T}\left(h^{*}, \xi_{G}, t\right) \tilde{G}
$$

When the abatement policy is announced at time $t=0$, the capital stock and hence the rate of return on physical capital are fixed. Consequently, the entire burden of the lump-sum tax is borne by labour (see below). If the policy is adopted gradually, the capital stock rises at first so that the interest rate falls initially. As time elapses, however, the decumulation of the capital stock causes the rate of return to rise to a higher level than before the shock. By substitution the steady-state capital stock (3.5) into (3.7), we obtain the long-run effect on the interest rate:

$$
\tilde{r}(\infty)=\left[\frac{(r-\rho) \varepsilon_{L}}{r \varepsilon_{L} \omega_{C}+\left(\varepsilon_{L}-\omega_{G}\right)(r-\rho)}\right] \tilde{G} \geq 0 .
$$

In the presence of overlapping generations (which implies $r>\rho$ ), the long-run rate of return on physical capital exceeds its initial steady-state equilibrium value. Thus, capital owners are actually better off in the long run as a result of the higher lump-sum taxes. With infinitely-lived agents (i.e. $\lambda=0$ and $r=\rho$, see Judd, 1985), however, the long-run interest rate is fixed by the exogenously given rate of time preference, $\rho$.

After-tax wages (net of lump-sum taxes, i.e. $W^{N}(t) \equiv W(t)-T(t)$ ) mirror the behaviour of the interest rate. By employing $\tilde{W}(t)=\left(1-\varepsilon_{L}\right) \tilde{K}(t)$ and $\tilde{T}(t)=\tilde{G}(t)$, we find for the after-tax wage rate:

$$
\tilde{W}^{N}(t)=\varepsilon_{L}\left(1-\varepsilon_{L}\right) \tilde{K}(t)-\tilde{G}(t)
$$

where $\tilde{W}^{N}(t) \equiv \mathrm{d} W^{N}(t) / Y=\varepsilon_{L} \tilde{W}(t)-\tilde{G}(t)$. The first term at the right-hand side of (3.8) represents the positive effect of the capital stock on the marginal product of labour and hence the before-tax wage rate, while the second term on the right-hand side stands for the detrimental effect of higher lump-sum taxes on the net wage. On impact, higher lump-sum taxes reduce after-tax wages, unless the policy is introduced gradually (i.e. $\tilde{G}(0)=0)$ in which case $\tilde{W}^{N}(0)=0$. Although wages may rise initially if the policy is introduced gradually, the eventual erosion of the capital stock puts wages on a downward path. By using (3.8) and (3.5), we can derive that:

Even in the absence of overlapping generations, long-run wages decline as a result of the lump- 


$$
\tilde{W}^{N}(\infty)=-\left[\frac{\left[\varepsilon_{L}-\omega_{G}+\left(1-\varepsilon_{L}\right) \varepsilon_{L}\right](r-\rho)+r \varepsilon_{L} \omega_{C}}{r \varepsilon_{L} \omega_{C}+\left(\varepsilon_{L}-\omega_{G}\right)(r-\rho)}\right] \tilde{G}<0 .
$$

sum taxes needed to finance the additional public abatement.

\subsection{The ecology}

The long-run quality of the environment improves for two distinct reasons, which are represented by the two terms at the right-hand side of expression (3.9):

$$
\tilde{E}(\infty)=\alpha_{G} \tilde{G}+\left[\frac{\alpha_{K}(r-\rho)}{r \varepsilon_{L} \omega_{C}+\left(\varepsilon_{L}-\omega_{G}\right)(r-\rho)}\right] \tilde{G}>0 .
$$

The first term at the right-hand side of (3.9) reveals that more public abatement directly improves the environment. The second term represents the positive environmental effects associated with a lower polluting capital stock. In particular, in the presence of overlapping generations (i.e. $r>\rho$ because $\lambda>0$ ), the long-run capital stock declines due to intergenerational redistribution away from future towards current generations.

By substituting the time paths for abatement and the capital stock (represented by, respectively, (3.1) and (3.4)) into the environmental equation (T.4') in Table 2, and solving the resulting differential equation subject to the initial condition $\tilde{E}(0)=0$, we obtain the following time path for the quality of the environment:

$$
\begin{aligned}
\tilde{E}(t)= & \alpha_{G} \tilde{G} \mathrm{~A}\left(\alpha_{E}, \xi_{G}, t\right)-\alpha_{K} \tilde{K}(\infty) \mathrm{A}\left(\alpha_{E}, h^{*}, t\right) \\
& -\left(\frac{\alpha_{K} r\left[r-\rho+\xi_{G}\right]}{\left(1-\varepsilon_{L}\right)\left(r^{*}+\xi_{G}\right)}\right) \tilde{G} \mathrm{~T}\left(\alpha_{E}, h^{*}, \xi_{G}, t\right),
\end{aligned}
$$

where $\mathrm{A}\left(\alpha_{E}, \alpha_{i}, t\right)$ represents a multiple adjustment term:

$$
\begin{aligned}
& \mathrm{A}\left(\alpha_{E}, \alpha_{i}, t\right) \equiv 1-\left(\frac{\alpha_{i} e^{-\alpha_{E} t}-\alpha_{E} e^{-\alpha_{i} t}}{\alpha_{i}-\alpha_{E}}\right) \text { for } \alpha_{i} \neq \alpha_{E} \\
& 1-\left(1+\alpha_{E} t\right) e^{-\alpha_{E} t} \quad \text { for } \alpha_{i}=\alpha_{E} \text {, }
\end{aligned}
$$


and $\mathrm{T}\left(\alpha_{E}, \alpha_{1}, \alpha_{2}, t\right)$ stands for a (temporary) multiple transition term:

$$
\begin{array}{cl}
\left.\mathrm{T}\left(\alpha_{E}, \alpha_{1}, \alpha_{2}, t\right) \equiv\left(\frac{\alpha_{E}}{\alpha_{E}-\alpha_{1}}\right) \mathrm{T}\left(\alpha_{1}, \alpha_{2}, t\right)-\mathrm{T}\left(\alpha_{E}, \alpha_{2}, t\right)\right] & \text { for } \alpha_{1} \neq \alpha_{E} \\
\alpha_{E} t^{2} e^{-\alpha_{E} t} / 2 & \text { for } \alpha_{1}=\alpha_{2}=\alpha_{E} .
\end{array}
$$

Lemmas A.3 and A.4 of Bovenberg and Heijdra (1998) show that the multiple adjustment terms are non-negative, S-shaped, and increasing functions of time, and that the multiple transition term is a non-negative, single-peaked, bell-shaped function of time. ${ }^{14}$ The multiple adjustment terms exhibit an adjustment path that is determined by a weighted average of two adjustment speeds, with the largest weight being attached to the slowest moving component. For example, if the ecological system adjusts more slowly than the capital stock (i.e. $\alpha_{E}<h^{*}$ ), the ecological adjustment speed $\alpha_{E}$ carries the largest (i.e., positive) weight in the adjustment term $\mathrm{A}\left(\alpha_{E}, h^{*}, t\right)$. Indeed, the environment improves slowly for three reasons: First, the policy is introduced slowly (if $\xi_{G} \ll \infty$ ). Second, the capital stock decumulates only gradually. Third, the stock-flow dynamics of the environment slow down the adjustment.

The first term at the right-hand side of (3.10) represents the direct beneficial effect of more public abatement on the quality of the environment. Here the adjustment speed depends on both the speed at which the policy is phased in (represented by $\xi_{G}$ ) and the speed at which the environment regenerates $\left(\alpha_{E}\right)$.

The second term at the right-hand side of (3.10) represents the positive environmental effect due to a reduction in the polluting capital stock. In the presence of overlapping generations, the long-run capital stock falls. If the birth rate is zero, however, the long-run capital stock remains constant (see equation (3.5) with $r=\rho$ ), and the second term at the right-hand side of (3.10) drops out. The adjustment term indicates that the resulting environmental adjustment occurs only slowly as both the capital stock adjusts only gradually and the environment regenerates slowly.

The third term at the right-hand side of (3.10) shows that gradual (rather than abrupt) introduction of the abatement policy yields temporary adverse effects on the environment. Intuitively, economic agents accumulate more capital in the short run in anticipation of higher taxes (see (3.3)). The associated temporarily larger capital stock causes additional pollution in the short run.

The first two terms at the right-hand side of (3.10) give rise to a steady improvement in environmental quality, but the third term works in the direction of a temporary deterioration. Hence, although environmental quality improves in the long run, it may well decline in the short run as a result of a temporary boost to capital accumulation. In particular, environmental quality 
worsens initially if:

$$
\left(\frac{\alpha_{K}}{\alpha_{G}}\right)\left(\frac{1}{1-\varepsilon_{L}}\right)\left(\frac{r^{*}-(r-\rho)}{r^{*}}\right)\left(\frac{r}{r^{*}+\xi_{G}}\right)>1 .
$$

The initial worsening of the environment requires that abatement is increased only very gradually (i.e., $\xi_{G}$ small) while horizons are long (i.e., $r-\rho=\lambda\left(1-\omega_{H}\right)$ is small). In that case, forward-looking households reduce their short-run consumption substantially in anticipation of the higher lump-sum taxes associated with more future public spending. Moreover, compared to abatement, capital should exert a relatively strong effect on environmental quality (i.e., $\alpha_{K} / \alpha_{G}\left(1-\varepsilon_{L}\right)$ is large) for the quality of the environment to fall in the short run. If the policy is phased in instantaneously $\left(\xi_{G} \rightarrow \infty\right)$, anticipation effects are absent. Accordingly, the third term on the right-hand side of (3.10) vanishes, and adjustment of the environmental quality is monotonous. Proposition 3.2 summarizes these effects.

PROPOSITION 3.2: The solution path for environmental quality (represented by (3.10)) satisfies the following properties:

(i) If the policy is introduced slowly and the birth rate is low, the environmental quality may deteriorate at first before improving later.

(ii) If the policy is introduced abruptly, environmental quality increases monotonically.

PROOF: See Bovenberg and Heijdra (1998).

\subsection{No overlapping generations: The efficiency case for public abatement}

The welfare effects of public abatement can be analyzed by employing the methods developed for the infinite horizon model by Judd $(1982,1985,1987)$ and extended to overlapping generations by Bovenberg $(1993,1994)$. In the presence of environmental amenities, welfare effects can be decomposed into two components. The first component represents the change in non-environmental welfare and is denoted by $\mathrm{d} U_{N E}(0)$. The second component measures the change in environmental welfare and is denoted by $\mathrm{d} U_{E}(0)$.

In the absence of overlapping generations and with an abrupt shock $\left(\xi_{G} \rightarrow \infty\right)$, nonenvironmental welfare of the representative agent is given by:

$$
\rho \mathrm{d} U_{N E}(0)=-\tilde{G} /\left(1-\omega_{G}\right)
$$

Non-environmental welfare declines on account of the higher lump-sum taxes required to finance 
the additional abatement. The environmental benefits of public abatement yield the following increase in environmental utility:

$$
\rho \mathrm{d} U_{E}(0)=\left[\frac{\alpha_{G} \alpha_{E}}{\rho+\alpha_{E}}\right] \tilde{G}>0,
$$

Overall welfare is given by the weighted sum of private and environmental welfare:

$$
\mathrm{d} U(0) \equiv \mathrm{d} U_{N E}(0)+\gamma_{E} \mathrm{~d} U_{E}(0)
$$

For each positive value of the initial abatement share, we can employ (3.11) to compute the environmental weight, $\hat{\gamma}_{E}$, for which the abatement share would be optimal, i.e. $\hat{\gamma}_{E} \equiv-\mathrm{d} U_{N E}(0) / \mathrm{d} U_{E}(0)$. Alternatively, for each value of $\gamma_{E}$, we can find the abatement share for which the overall marginal welfare effect is zero. This is in fact the optimal share of public abatement $\hat{\omega}_{G}$ :

$$
\hat{\omega}_{C} \equiv 1-\hat{\omega}_{G} \equiv \frac{\rho+\alpha_{E}}{\alpha_{E} \alpha_{G} \gamma_{E}}
$$

Equation (3.12) implies the following effects for the optimal abatement share: $\partial \omega_{G} / \partial \gamma_{E}>0$, $\partial \omega_{G} / \partial \alpha_{K}=0, \partial \omega_{G} / \partial \alpha_{G}>0$, and $\partial \omega_{G} / \partial \alpha_{E}>0$ (see Bovenberg and Heijdra (1998)). A strong concern for the environment implies a high optimal abatement share. The same holds true for a high elasticity of the steady-state environment with respect to abatement. Moreover, the higher is the speed of regeneration of the environment, the more substantial are the environmental benefits from additional abatement, and hence the higher is the optimal abatement share.

\subsection{Intergenerational welfare}

In the presence of overlapping generations, the tax burden associated with additional public abatement affects the various generations in different ways. This sub-section explores the intergenerational distribution effects.

\subsubsection{Non-environmental welfare}

For existing generations, the change in non-environmental welfare amounts to a weighted average of the jump in consumption that occurs at time $t=0$ (i.e., $\tilde{C}(0)$ ) and the Laplace transform of changes in the interest rate:

$$
(\rho+\lambda) \mathrm{d} U_{N E}(v, 0)=\left[e^{(r-\rho) v} / \omega_{H}\right] \tilde{C}(0)+r \mathscr{L}\{\tilde{r}, \rho+\lambda\}, \quad v \leq 0 .
$$

The first term at the right-hand side of (3.13) represents the impact of higher lump-sum taxes on 
the initial consumption level while the second term stands for the effect of changes in the interest rate on the growth rate of consumption. The second term can be written as:

$$
\mathscr{L}\{\tilde{r}, \rho+\lambda\}=\left(\frac{r \varepsilon_{L}}{1-\varepsilon_{L}}\right)\left(\frac{\tilde{G}}{\rho+\lambda+h^{*}}\right)\left[\frac{r-\rho}{r^{*}(\rho+\lambda)}-\frac{r-\rho+\xi_{G}}{\left(r^{*}+\xi_{G}\right)\left(\rho+\lambda+\xi_{G}\right)}\right]
$$

The sign of the Laplace transform of changes in the interest rate is ambiguous and depends (among other things) on the probability of death and the speed at which the policy is introduced. If agents exhibit infinite lives $(\lambda=0$ and $r=\rho$ ), the effect of interest changes on non-environmental welfare is unambiguously negative if the policy is introduced gradually ( $\xi_{G}$ finite). This is due to anticipation effects, which cause a temporary increase in the capital stock and hence a temporary drop in the rate of interest. If the policy is introduced instantaneously (i.e. $\xi_{G} \rightarrow \infty$ ) and overlapping generations are absent $(\lambda=0$ and $r=\rho)$, the capital stock, and hence the interest rate, remain constant.

Matters are slightly more involved if agents feature finite lives. In that case, the sign of the Laplace transform of interest rate changes in (3.14) depends on both the probability of death $(\lambda)$ and the speed with which the policy is introduced. If the policy is introduced instantaneously $\left(\xi_{G} \rightarrow \infty\right)$, the capital stock declines monotonically. Consequently, the Laplace transform of changes in the interest rate is unambiguously positive. For very old agents (with a very negative index $v$ ), the positive second term at the right-hand side of (3.13) dominates the negative first term. Hence, these agents unambiguously enjoy higher non-environmental welfare, despite the higher tax level required to finance the abrupt increase in public abatement. The reason is that the very old are wealthy because they have had a long time to accumulate large stocks of financial wealth. Consequently, the elderly do not suffer much from the higher lump-sum taxes but benefit substantially from the rise in the interest rate.

Young agents who have been born just before the policy shock occurred (i.e. with an index $v$ close to zero), in contrast, suffer substantially from the higher lump-sum taxes. These generations hold little or no financial wealth and thus depend almost entirely on human wealth, the value of which declines on account of the higher lump-sum taxes. Hence, whereas the change in nonenvironmental utility experienced by existing generations is positive for the oldest generations, this non-environmental welfare effect becomes negative for younger households.

If lives are finite and the policy is introduced gradually, non-environmental utility of agents born at the time of the shock unambiguously declines. However, for very old agents, this welfare effect is ambiguous. The oldest generations face a loss in non-environmental welfare if both $r$ $\rho=\lambda\left(1-\omega_{H}\right)$ and $\xi_{G}$ are small, i.e., if lives are long and the policy is introduced only slowly. In that case, the anticipation effects are substantial (because $\xi_{G}$ is small) while the intergenerational 
distributional effects are only small (because $r-\rho=\lambda\left(1-\omega_{H}\right)$ is small). Accordingly, the short-run decline in the interest rate on account of the anticipation effects dominates the long-run increase in the interest rate on account of intergenerational distribution effects.

For generations who have not yet been borne at the time of the policy shock (i.e. so-called future generations whose generation index coincides with the historical time index, $t>0$ ), the time path for the change in non-environmental utility can be written as:

$$
\mathrm{d} U_{N E}(t, t)=\mathrm{d} U_{N E}(0,0)+\left[\mathrm{d} U_{N E}(\infty, \infty)-\mathrm{d} U_{N E}(0,0)\right] \mathrm{A}\left(h^{*}, t\right)+\Omega_{N E}\left(\xi_{G}\right) \mathrm{T}\left(h^{*}, \xi_{G}, t\right) \tilde{G}
$$

where $\Omega_{N E}\left(\xi_{G}\right)$ is a function of parameters and $\xi_{G}$, and where the non-environmental welfare effect for the generation born at the time of the policy shock, $\mathrm{d} U_{N E}(0,0)$, is given by expression (3.13) with $v=0$. For generations born in the new steady state, non-environmental welfare is given by:

$$
(\rho+\lambda) \mathrm{d} U_{N E}(\infty, \infty)=\frac{\tilde{C}(\infty)-\left(1-\omega_{H}\right) \tilde{K}(\infty)}{\omega_{H}}+\left(\frac{r}{\rho+\lambda}\right) \tilde{r}(\infty) .
$$

Generations born far into the future enjoy less non-environmental utility than future generations born earlier do because they have less physical capital to work with. Indeed, equation (3.8) shows that the decline in the capital stock causes after-tax wages to gradually fall over time. Hence, generations born in the new steady state are worse off in terms of non-environmental welfare than in the initial steady state. Proposition 3.3 summarizes the main features of non-environmental utility for various generations.

PROPOSITION 3.3: The solution paths for non-environmental utility of the various cohorts satisfy the following properties:

(i) The oldest generations gain unless the policy is introduced sufficiently slowly and the birth rate is sufficiently low. Furthermore, $\partial \mathrm{d} U_{N E}(v, 0) / \partial v<0$.

(ii) The generation born at the time of the shock loses regardless of the value of $\xi_{G}$. The loss is increasing in $\xi_{G}$ (i.e., $\mathrm{d} U_{N E}(0,0)<0$ and $\left.\partial \mathrm{d} U_{N E}(0,0) / \partial \xi_{G}<0\right)$.

(iii) The generations born in the new steady state loses regardless of the value of $\xi_{G}$ (i.e., $\left.\mathrm{d} U_{N E}(\infty, \infty)<0\right)$.

(iv) The generations born in the new steady state are worse off than the generations born at the time of the policy shock regardless of $\xi_{G}$ (i.e. $\left.\mathrm{d} U_{N E}(\infty, \infty)<\mathrm{d} U_{N E}(0,0)<0\right)$.

(v) In the absence of overlapping generations (i.e. $\lambda=0$ ), the representative households suffers a welfare loss regardless of the value of $\xi_{G}$. 
PROOF: See Bovenberg and Heijdra (1998).

\subsubsection{Environmental welfare}

All existing generations face the same probability of death and thus expect the same remaining life time. Accordingly, they experience the same boost in environmental utility on account of improved environmental quality:

$$
\begin{gathered}
\mathrm{d} U_{E}(0)=\mathscr{L}\{\tilde{E}, \rho+\lambda\}=\frac{\alpha_{E} \tilde{G}}{(\rho+\lambda)\left(\rho+\lambda+\alpha_{E}\right)} \times \\
{\left[\frac{\alpha_{G} \xi_{G}}{\rho+\lambda+\xi_{G}}-\frac{\alpha_{K} r \omega_{C}}{\left(1-\varepsilon_{L}\right)\left(\rho+\lambda+h^{*}\right)}\left(-\frac{r-\rho}{r^{*}}+\frac{\left(r-\rho+\xi_{G}\right)(\rho+\lambda)}{\left(r^{*}+\xi_{G}\right)\left(\rho+\lambda+\xi_{G}\right)}\right)\right]}
\end{gathered}
$$

The first term in square brackets at the right-hand side of (3.15) represents the direct positive impact on the environment of additional public abatement. The other terms represent the effect of changes in the capital stock on the environment. If the policy is introduced gradually, the capital stock rises at first before it falls to its lower long-run value. If the policy is introduced sufficiently slowly, the initial boost to capital accumulation, which pollutes the environment, dominates the long-run drop in polluting capital stock. Hence, the term in round brackets is negative if the speed with which the policy is introduced, $\xi_{G}$, is small. Rather paradoxically, existing generations may actually end up with lower environmental welfare if the policy is introduced slowly $\left(\xi_{G}\right.$ small), horizons are short (the death rate $\lambda$ is large), and abatement is not very effective $\left(\alpha_{G} / \alpha_{K}\right.$ small). During their lifetimes, these generations experience a long transition period during which the environment worsens due to the temporary boost in investment.

Environmental utility unambiguously rises in the long run, both because the capital stock falls (see (3.5)) and because of the direct positive environmental effects of more public abatement:

$$
\mathrm{d} U_{E}(\infty)=\frac{\tilde{E}(\infty)}{\rho+\lambda}=\left[\alpha_{G}+\frac{\alpha_{K} r(r-\rho)}{\left(1-\varepsilon_{L}\right) r^{*} h^{*}}\right] \frac{\tilde{G}}{\rho+\lambda}
$$

The comparison of (3.15) and (3.16) reveals that future generations enjoy a higher level of environmental utility than existing generations do (i.e., $\mathrm{d} U_{E}(\infty)>\mathrm{d} U_{E}(0)$ ). Moreover, the adjustment path of environmental utility need not be monotonous if the policy is introduced gradually. 
The main characteristics of the time path of environmental utility are summarized in Proposition 3.4.

PROPOSITION 3.4: The solution path for environmental utility satisfies the following properties:

(i) Existing generations gain unless the policy is introduced very slowly $\left(\xi_{G}\right.$ low), the birth rate is high, and abatement is not very effective $\left(\alpha_{K} / \alpha_{G}\right.$ large $)$.

(ii) The generations born in the new steady-state gain regardless of the value of $\xi_{G}$ (i.e., $\left.\mathrm{d} U_{E}(\infty)>0\right)$.

(iii) Future generations gain more than present generations do (i.e. $\mathrm{d} U_{E}(\infty)>\mathrm{d} U_{E}(0)$ ).

(iv) If the policy is introduced instantaneously $\left(\xi_{G} \rightarrow \infty\right)$, non-environmental welfare rises monotonically.

PROOF: See Bovenberg and Heijdra (1998).

\subsubsection{Total welfare: Pareto improving reforms}

Overall welfare amounts to a weighted sum of non-environmental and environmental welfare:

$$
\begin{gathered}
\mathrm{d} U(v, 0) \equiv \mathrm{d} U_{N E}(v, 0)+\gamma_{E} \mathrm{~d} U_{E}(0), \quad v \leq 0, \\
\mathrm{~d} U(t, t) \equiv \mathrm{d} U_{N E}(t, t)+\gamma_{E} \mathrm{~d} U_{E}(t), \quad t \geq 0 .
\end{gathered}
$$

If the policy is introduced abruptly $\left(\xi_{G} \rightarrow \infty\right)$, the older generations reap the largest benefits of the generations that are alive at $t=0$. While all currently living generations enjoy the same environmental improvements, the elderly suffer less from the increase in lump-sum taxes because human wealth is a relatively small wealth component for the elderly. Among the generations that are yet to be born at $t=0$, the oldest generations (i.e. the generations that are born immediately after $t=0)$ benefit the most only if the weight of environmental welfare, $\gamma_{E}$, is very small. The reason is that the older generations have a larger capital stock to work with than the younger generations and thus enjoy higher wages and non-environmental welfare. However, the younger cohorts of the generations that are born after $t=0$ experience a larger improvement in environmental welfare and thus, if the weight of environmental welfare $\gamma_{E}$ is large, experience a larger gain in overall welfare than the older generations born earlier after $t=0$.

An abrupt increase in public abatement is Pareto welfare-improving if the overall welfare of all future generations increases. The minimum level of the environmental utility weight for 
which the reform is Pareto-welfare improving is given by:

$$
\gamma_{E}^{P} \equiv \max \left[\frac{-\mathrm{d} U_{N E}(0,0)}{\mathrm{d} U_{E}(0)}, \frac{-\mathrm{d} U_{N E}(\infty, \infty)}{\mathrm{d} U_{E}(\infty)}\right]
$$

The numerical simulations in sub-section 3.6 below indicate that for reasonable parameter values the generation born at $t=0$ is the critical generation, i.e. the generation for which the environmental weight needs to be largest in order for the generation to benefit in terms of overall welfare:

$$
\gamma_{E}^{P} \equiv-\frac{\mathrm{d} U_{N E}(0,0)}{\mathrm{d} U_{E}(0)}
$$

The oldest of the future generations is the critical generation because the gain in environmental welfare rises faster with the date of birth of a generation than the absolute value of the loss in nonenvironmental welfare does. Indeed, the literature on overlapping generations models suggest that, for reasonable values for the birth rate, the crowding-out effects of higher public spending on private saving and investment are quite small (see, for example, Auerbach and Kotlikoff (1987, pp. 97-101) and Romer (1988)). Hence, in view of only limited capital decumulation, wages, and thus non-environmental welfare, do not decline much over time.

Another reason for why the oldest future generations are the critical generations is the following. The non-environmental losses on account of capital decumulation are accompanied by environmental gains due to a smaller polluting capital stock. Hence, crowding-out of private investment implies that the younger future generations not only bear larger non-environmental costs but also enjoy larger environmental benefits than older future generations do. Moreover, the environmental benefits on account of crowding out of private investment are supplemented by the direct environmental gains due to more public abatement. These latter environmental gains accrue mainly to younger, future generations because these gains occur only gradually through time because of stock-flow dynamics. Hence, the additional environmental gains enjoyed by future generations (due to not only crowding out of polluting capital but also the direct positive effect of more abatement on environmental quality) dominate the additional non-environmental costs suffered by these generations (due to the adverse effects of crowding out on wages).

With a gradual implementation of environmental policy $\left(\xi_{G} \ll \infty\right)$, the elderly among those alive at $t=0$ do no longer necessarily benefit. In particular, the temporary increase in capital accumulation on account of anticipation effects hurts the elderly through two channels, namely a temporarily lower return on capital and a dirtier environment. The temporary increase in capital accumulation has consequences also for the generations born immediately after $t=0$. On the one 
hand, these generations have more capital to work with and thus benefit from higher wages. On the other hand, they live in a dirtier world. Which factor dominates depends on the environmental weight in utility.

\subsection{Numerical illustration}

This sub-section presents numerical simulations for an abrupt increase of public abatement in a model with plausible parameter values provided at the bottom of Table 3. This table shows how the minimum level of the environmental utility weight for which higher public abatement is Pareto-welfare improving depends on the initial abatement share and the birth rate. The initial abatement share indicates how ambitious environmental policy is in the initial equilibrium while the birth rate reflects the importance of intergenerational redistribution between disconnected generations.

The first panel of Table 3 explores the case of a representative, infinitely lived household as a benchmark. The third and fourth columns contain the impacts on, respectively, nonenvironmental and environmental welfare for the different values of the initial production share of abatement included in the first column. The second column employs the results from the third and fourth columns to compute the environmental welfare weight $\gamma_{E}^{P}=-\mathrm{d} U_{N E}(0) / \mathrm{d} U_{E}(0)$ for which the gain in environmental welfare exactly offsets the loss in non-environmental welfare so that overall welfare is unaffected by the marginal increase in public abatement. For this environmental utility weight, the abatement share recorded in the first column is optimal. It can be interpreted as the optimal abatement share from a pure efficiency perspective; a zero birth rate implies that generations are connected so that intergenerational redistribution is absent.

The second and third panels of Table 3 involve overlapping, disconnected generations. Each generation experiences distinct welfare effects. Accordingly, the environmental utility weight that makes households indifferent about a marginal increase in public abatement is specific to each generation. The environmental welfare weights contained in the fifth column (for a birth rate of 0.02) and the eighth column (for a birth rate of 0.06) are the minimum welfare weights ensuring that no generation loses from more public abatement. These weights, which assess the scope for Pareto-improving reforms, require the computation of the environmental welfare weight that makes the worst-off generation indifferent about higher abatement. As already noted in sub-section 3.5, this 'critical' generation is the oldest of the future generations, i.e. the generation that is born at the time of the abrupt increase in public abatement. This generation benefits least from the improvement in environmental quality because the environment improves only gradually due to the stock-flow dynamics. Of all future generations, this particular generation experiences also the 
smallest loss in non-environmental welfare because its wages are hurt least by capital decumulation. However, the crowding-out effects on capital accumulation are quite small (see subsection 3.5). Hence, the younger generations are better off in terms of overall welfare than the older future generations are; whereas they do not suffer much more in terms of non-environmental welfare than older generations, they benefit substantially more from a cleaner environment. Figure 3 does indeed show that the date of birth of a future generation exerts a much larger impact on environmental welfare than on non-environmental welfare, which is rather flat to the right of $v=0$. Figure 4 reveals how the date of birth of a generation affects the generation-specific minimum environmental welfare weights.

The comparison of the panels indicate that intergenerational disconnectedness complicates environmental policy. In particular, for each initial abatement share, the minimum environmental utility weight that ensures that everybody gains is smallest in the absence of disconnected generations (i.e. $\lambda=0$ ). However, an increase in the birth rate (compare the second and third panels) exerts only relatively small effects on the minimum environmental utility weight. The reason is that the distribution of the gain in environmental welfare is quite similar to the distribution of the loss in non-environmental welfare. In particular, whereas the youngest generations among the future generations benefit the most from improved environmental quality, they lose most on account of the higher lump-sum taxes. Hence, the higher lump-sum taxes act like benefit taxes. A higher birth rate implies more substantial crowding-out effects on private capital accumulation. The environmental benefits in terms of a smaller polluting capital stock and non-environmental costs in terms of lower wages occur at the same time. Accordingly, the same generations experience both the benefits and the costs.

Table 4 shows how generations alive at the time of the abrupt increase in public abatement would vote in case higher abatement would be put to a vote. $\sigma(\%)$ denotes the proportion of the population who gain in overall welfare and who would thus vote in favour of more public abatement. With high birth rates, the interests of the electorate are more diverse. Accordingly, the electorate tends to be more divided than with low birth rates. In the latter case, the voters are more homogeneous in favouring or rejecting higher public abatement.

Table 4 contains also a number of welfare indicators. These indicators confirm the analytical results in general and Propositions 3.2 and 3.3 in particular. Moreover, the numerical results indicate that non-environmental welfare for future generations does not fall much with date of birth (i.e. $\mathrm{d} U_{N E}(\infty, \infty)$ is not much less than $\left.\mathrm{d} U_{N E}(0,0)\right)$. Accordingly, the generation born at the time of the policy shock is indeed the critical generation in determining the minimal environmental utility weight for which no generation suffers a loss in overall welfare (see also Figure 4). 


\section{Intergenerational redistribution policy}

This section explores the role of public debt in eliminating the intergenerational inequities resulting from an abrupt increase in public abatement (i.e. $\xi_{G} \rightarrow \infty$ ). The first sub-section employs public debt to ensure that all current generations (i.e. generations alive at the time of the policy shock) are equally well off. The second sub-section adopts a more complex debt policy so that all (i.e. not only current but also future) generations experience the same change in overall welfare.

\subsection{Compensating current generations}

Section 3 showed that the various current generations are affected quite differently by an abrupt increase in public abatement. Whereas all current generations enjoy the same improvement in environmental welfare (see Proposition 3.4), these generations experience rather diverging impacts on non-environmental welfare. In particular, the higher lump-sum taxes hit the younger generations, who rely heavily on human wealth, harder than the older generations who have accumulated more financial capital. Accordingly, in contrast to the elderly, the young lose in terms of non-environmental welfare (see Proposition 3.3).

To offset the intergenerational distributional effects in favour of the older, current generations, the government needs to levy age-specific taxes. A once-off wealth tax $\left(\tau_{K}\right)$ levied at the time of the unexpected policy shock on the stock of financial wealth acts like such an agespecific tax. The incidence of this tax features the required relationship with age because holdings of financial wealth rise with age in the initial steady state. Bovenberg and Heijdra (1998) show that the following once-off capital levy ensures that all generations alive at the time of the policy shock suffer the same decline in non-environmental welfare:

$$
\tau_{K}=-\tilde{C}(0)=-\frac{\tilde{B}(0)}{1-\varepsilon_{L}}=\frac{\tilde{G}}{\omega_{C}}>0
$$

where $\tilde{B}(0) \equiv r \mathrm{~d} B(0) / Y$ stands for the discrete drop in public debt at time $t=0$ resulting from the revenue raised by the once-off capital levy.

The capital levy neutralizes the intergenerational distributional effects on nonenvironmental welfare not only for current generations but also for future generations if government debt remains constant after the initial drop $(\tilde{B}(t)=\tilde{B}(0)$ for all $t \geq 0)$. In that case, the interest income on the additional public assets reduces the required increase in lump-sum taxes. The capital levy combined with the lower additional taxes on human capital ensures that the additional tax burden due to higher public spending is proportional to consumption rather than 
human capital. Accordingly, the additional tax burden is distributed equally over all generations so that all generations experience the same drop in non-environmental utility:

$$
\mathrm{d} U_{N E}(v, 0)=\mathrm{d} U_{N E}(t, t)=-\frac{\tilde{G}}{(\rho+\lambda) \omega_{C}}<0,
$$

for $v \leq 0$ and $t \geq 0$.

With all generations suffering the same decline in non-environmental welfare, capital accumulation is no longer crowded out on account of intergenerational distributional effects in favour of the older generations (as is the case without the wealth tax, see sub-section 3.1). Indeed, without intergenerational distributional effects in terms of non-environmental welfare, aggregate consumption is no longer redistributed from the future to the present. In terms of Figure 2, the capital levy shifts the MKR curve down such that this curve intersects the new IS curve directly below $E_{0}$ in point $D$. Crowding out of household consumption is one-for-one for each unit of additional public abatement. Since private capital accumulation is thus unaffected, all transitional dynamics disappears from the non-environmental system, i.e. $\tilde{K}(t)=\tilde{Y}(t)=\tilde{r}(t)=\tilde{W}(t)=0$ and $\tilde{C}(t)=-$ $\tilde{G} / \omega_{C}$ for all $t \geq 0$.

Without changes in the polluting capital stock, environmental quality is affected only by additional public abatement. Accordingly, the environment improves gradually according to $\tilde{E}(t)=\alpha_{G} \tilde{G A}\left(\alpha_{E}, t\right)$ on account of stock-flow dynamics between the flow of abatement and the stock of environmental capital. As a result of this gradual improvement in environmental quality, younger generations enjoy the largest gain in environmental welfare:

$$
\mathrm{d} U_{E}(t)=\frac{\alpha_{G} \tilde{G}}{\rho+\lambda}\left[1-\left(\frac{\rho+\lambda}{\rho+\lambda+\alpha_{E}}\right) e^{-\alpha_{E} t}\right]>0,
$$

for $t \geq 0$.

With all generations suffering the same drop in non-environmental welfare but current generations enjoying the smallest boost in environmental welfare, these generations are the 'critical' generation in determining the scope for a Pareto-improving policy. The overall welfare gain to current generations amounts to:

$$
(\rho+\lambda) \mathrm{d} U(v, 0)=\left[-\frac{1}{\omega_{C}}+\frac{\gamma_{E} \alpha_{G} \alpha_{E}}{\rho+\lambda+\alpha_{E}}\right] \tilde{G}, \quad \text { for } v \leq 0 .
$$

The abatement share $\omega_{G}\left(\equiv 1-\omega_{C}\right)$ ensuring $\mathrm{d} U(v, 0)=0$ is the largest abatement share so that all present generations are at least equally well off (and which thus, in view of (4.2), makes all future 
generations strictly better off):

$$
\omega_{C}^{P I} \equiv 1-\omega_{G}^{P I}=\frac{\rho+\lambda+\alpha_{E}}{\gamma_{E} \alpha_{G} \alpha_{E}} .
$$

This expression for the Pareto-improving abatement share is similar to the one determining the optimal abatement share in the representative-agent case (viz. equation (3.12)). ${ }^{15}$ The only difference between (3.12) and (4.3) is that (4.3) features a higher "effective" discount rate, $\rho+\lambda$, in order to account for finite lives. Ceteris paribus the ecological and taste parameters, $\alpha_{E}, \alpha_{G}$, and $\gamma_{E}$, a larger birth rate, which indicates that generations are more disconnected, produces a lower Pareto-improving share of public abatement, i.e. $\partial \omega_{G}^{P I} \partial \lambda<0$. Intuitively, the shorter horizons implied by the larger birth rate imply that current generations benefit less from the environmental improvements that materialize only in the future.

\subsection{Egalitarian policy}

If the abatement share is set equal to the abatement share derived in (4.3), all current generations are indifferent. All future generations, in contrast, are strictly better off due to larger gains in environmental welfare. This suggests that a more ambitious Pareto-improving environmental policy is feasible if the government redistributes resources away from future generations to current generations. Accordingly, the generations that benefit the most from the environmental improvements compensate the generations that benefit the least from higher environmental quality. Public debt policy can be employed to ensure that the additional taxes required to finance the additional public abatement are born by those who benefit from the environmental gains produced by the additional abatement. In this way, the additional taxes are in fact benefit taxes since these taxes correspond to the benefits from the spending that these taxes allow. Public debt thus separates equity concerns from efficiency considerations, thereby ensuring that all generations benefit from an efficiency enhancing reform.

In computing the benefit taxes, we impose the requirement that all generations benefit equally from the environmental policy, i.e. $\mathrm{d} U(v, 0)=\mathrm{d} U(t, t)=\pi$ for all $v \leq 0$ and $t \geq 0$. By thus spreading the gains equally over all generations, we can interpret $\pi$ as the pure efficiency gain associated with environmental policy. ${ }^{16}$ To find the intergenerational transfers that yield such a so-called egalitarian policy, we parameterize the time path of public debt as follows:

$$
\tilde{B}(t)=\tilde{B}(0)+\sum_{i=1}^{2} \mathrm{~A}\left(\xi_{i}, t\right) b_{i},
$$

with $\xi_{i}>0$ and $b_{i}$ both finite, so that the bond path is stable and converges in the long run to 
$\tilde{B}(\infty) \equiv \tilde{B}(0)+b_{1}+b_{2}$. When raising public abatement, the government thus has five instruments, $\tilde{B}(0)$, $b_{i}$ and $\xi_{i}(i=1,2)$, at its disposal to redistribute resources between generations. Bovenberg and Heijdra (1998) show that these instruments are sufficient to arrive at an egalitarian policy. ${ }^{17}$

As in the previous sub-section, the government levies a one-time tax on the existing stock of financial wealth at time $t=0$ in order to equalize welfare for all existing generations:

$$
\tau_{K}=-\tilde{C}(0)=-\frac{\tilde{B}(0)}{1-\varepsilon_{L}}=\frac{\tilde{G}}{\omega_{C}}-\left(\frac{r-\rho}{\left(1-\varepsilon_{L}\right)\left[r^{*}-(r-\rho)\right]}\right) \sum_{i=1}^{2} \frac{b_{i} \xi_{i}}{r^{*}+\xi_{i}}>0 .
$$

By imposing a smaller capital levy than in section 4.1 (see equation (4.1)), the loss in nonenvironmental welfare suffered by current generations is smaller. In terms of Figure 2, the downward shift of the MKR curve is smaller, and also the drop in consumption on impact is less pronounced. As a direct consequence, investment falls at impact and both consumption and capital are crowded out in the long run:

$$
\begin{gathered}
\tilde{C}(\infty)=-\frac{\tilde{G}}{\omega_{C}}-\left(\frac{r(r-\rho)}{\left(1-\varepsilon_{L}\right)\left[r^{*}-(r-\rho)\right] h^{*}}\right) \sum_{i=1}^{2} \frac{b_{i}\left[r^{*}+\xi_{i}-(r-\rho)\right]}{r^{*}+\xi_{i}}<\frac{\tilde{G}}{\omega_{C}}<0, \\
\tilde{K}(\infty)=\left(\frac{-r(r-\rho) \omega_{C}}{\left(1-\varepsilon_{L}\right)^{2}\left[r^{*}-(r-\rho)\right] h^{*}}\right) \sum_{i=1}^{2} \frac{b_{i}\left[r^{*}+\xi_{i}-(r-\rho)\right]}{r^{*}+\xi_{i}}<0 .
\end{gathered}
$$

The redistribution of non-environmental resources away from future towards current generations is thus associated with crowding out of man-made capital. In this way, natural capital replaces man-made capital. Whereas future generations benefit from additional amenities associated with a larger stock of natural capital, they lose on account of lower before-tax wages due to a smaller stock of man-made capital.

Table 4 reports estimates of the efficiency gains for different values of the birth rate, $\lambda$, and the initial abatement share, $\omega_{G}$ (see the entries for $\pi$ ). If the initial abatement share is zero, the efficiency gains are positive for all birth rates considered. Debt policy thus allows the welfare gains to be redistributed from future towards current generations (of whom many would lose without debt policy even for modest values of $\lambda$ ). At the relatively high birth rate of 0.1 , political support would be inadequate without debt policy as a majority of the current generations would vote against higher public abatement. With debt policy, in contrast, all generations are strictly better off so that political support is unanimous.

The bottom of Table 4 presents various abatement shares for each birth rate. $\hat{\omega}_{G}$ represents 
the maximum abatement share at which all generations are just indifferent about a marginal increase in abatement if debt policy ensures that all generations experience the same change in overall welfare (as explained in this sub-section). The results reveal that, at high birth rates, this abatement share substantially exceeds the corresponding maximum abatement share (computed in (4.3)) if public debt ensures only that all current generations are indifferent (see sub-section 4.1), i.e. $\hat{\omega}_{G}>\omega_{G}^{P I}$. At these high birth rates, this share is also substantially larger than the abatement share for which exactly half of the current generations in indifferent in the absence of any public debt policy. i.e. $\hat{\omega}_{G}>\omega_{G}^{M R}$. This suggests that public debt plays an important role in facilitating the political support for environmental policy if high birth rates indicate that various generations are rather disconnected.

\section{Conclusions}

This paper has employed an overlapping-generations model to explore two objections that are often raised against more public spending on the natural environment, namely crowding-out of physical capital and intergenerational redistribution at the expense of current generations. The analysis shows that these objections are not very strong. In particular, the crowding-out effects are only small for realistic values of the birth rate. Moreover, the crowding-out effects help to limit the intergenerational redistributional effects by ensuring that younger, future generations, who benefit most from the environmental improvements, bear more of the costs of financing the higher public abatement. Indeed, a higher birth rate, which reflects more disconnectedness among generations, implies more crowding out of private investment in response to higher public abatement. The costs of capital decumulation in terms of lower wages are born by the same generations who benefit from a cleaner environment produced by the lower stock of polluting capital. A lower capital stock thus yields both non-environmental costs in terms of lower wages and environmental benefits in terms of a cleaner environment. These costs and benefits accrue at the same time and thus affect the same generations. The intergenerational redistributional effects of higher public abatement are limited also because the lump-sum taxes used to finance the higher public abatement act like benefit taxes: the youngest generations benefit the most from improved environmental quality but also lose the most on account of the higher lump-sum taxes.

The objections based on intergenerational redistribution can be eliminated completely through the judicious use of public debt. In particular, by taxing away the windfall gains to future generations and redistributing them to current generations, the net benefits from a tighter 
environmental policy are distributed more equally among the various generations. The associated crowding out of physical capital is offset by crowding in of natural capital. In effect, society substitutes natural for man-made capital. 


\section{References}

Auerbach, A.J. and L.J. Kotlikoff (1987). Dynamic Fiscal Policy. Cambridge: Cambridge University Press, 1987.

Becker, R.A. 'Intergenerational equity: The capital-environment trade-off.' Journal of Environmental Economics and Management, June 1982, 9, 165-185.

Blanchard, O.-J. 'Debt, deficits, and finite horizons.' Journal of Political Economy, April 1985, 93, 223-247.

Bovenberg, A.L. 'Investment promoting policies in open economies: The importance of intergenerational and international distributional effects,' Journal of Public Economics, May 1993, 51, 3-54.

Bovenberg, A.L. 'Capital taxation in the world economy.' In: F. van der Ploeg, Ed. Handbook of International Macroeconomics. Oxford: Basil Blackwell, 1994.

Bovenberg, A.L. and B.J. Heijdra. 'Environmental tax policy and intergenerational distribution.' Journal of Public Economics, January 1998, 67, 1-24.

Bovenberg, A.L. and B.J. Heijdra. 'Environmental abatement and intergenerational distribution: Mathematical appendix.' Mimeo, University of Groningen, September 1998.

Diamond, P.A. 'National debt in a neoclassical growth model.' American Economic Review, December 1965, 55, 1126-1150.

Fisher, W.H. and S.J Turnovsky. 'Public investment, congestion, and private capital accumulation.' Economic Journal, March 1998, 108, 399-413.

Gramlich, E.M. 'Infrastructure investment: A review essay.' Journal of Economic Literature, September 1994, 32, 1176-1196.

Howarth, R.B. 'Intergenerational competitive equilibria under technological uncertainty and an exhaustible resource constraint.' Journal of Environmental Economics and Management, November 1991, 21, 225-243.

and R.B. Norgaard. 'Intergenerational resource rights, efficiency, and social optimality.' Land Economics, February 1990, 66, 1-11.

and - 'Environmental valuation under sustainable development.' American Economic Review, Papers and Proceedings, May 1992, 82, 473-477.

John, A. and R. Pecchenino. 'An overlapping generations model of growth and the environment.' Economic Journal, November 1994, 104, 1393-1410.

D. Schimmelpfennig, and S. Schreft. 'Short-lived agents and the long-lived environment.' Journal of Public Economics, September 1995, 58, 127-141. 
Judd, K.L. 'An alternative to steady-state comparisons in perfect foresight models.' Economics Letters, 1982, 10, 55-59.

—. 'Short-run analysis of fiscal policy in a simple perfect foresight model.' Journal of Political Economy, April 1985, 93, 298-319.

- 'The welfare costs of factor taxation in a perfect-foresight model.' Journal of Political Economy, August 1987, 95, 675-709.

Marini, G. and F. van der Ploeg. 'Monetary and fiscal policy in an optimising model with capital accumulation and finite lives,' Economic Journal, September 1988, 98, 772-786.

Marini, G. and P. Scaramozzino. 'Overlapping generations and environmental control.' Journal of Environmental Economics and Management, July 1995, 29, 64-77.

Mourmouras, A. 'Conservationist government policies and intergenerational equity in an overlapping generations model with renewable resources.' Journal of Public Economics, June 1993, 51, 249-268.

Norgaard, R.B. 'Issues in asset aggregation and intergenerational transfers.' In: E. Lutz, Ed. Toward Improved Accounting for the Environment. Washington, DC: World Bank, 1993.

Pasek, J. 'Obligations to future generations: A philosophical note.' World Development, April 1992, 20, 513-521.

Romer, D. 'What are the costs of excessive deficits?' NBER Macroeconomics Annual, 1988, 3, 63110.

Turnovsky, S.J. and W.H. Fisher. 'The composition of government expenditure and its consequences for macroeconomic performance.' Journal of Economic Dynamics and Control, May 1995, 19, 747-786.

Yaari, M.E. 'Uncertain lifetime, life insurance, and the theory of the consumer.' Review of Economic Studies, April 1965, 32, 137-150. 
Table 3. Welfare effects

Infinite lives:

Finite lives:

\begin{tabular}{lllllllll}
$\lambda=0$ & \multicolumn{9}{c}{$\lambda=0.02$} & & & $\lambda=0.06$ \\
\\
$\gamma_{E}^{P}$ & $\mathrm{~d} U_{N E}(0)$ & $\mathrm{d} U_{E}(0)$ & $\gamma_{E}^{P O}$ & $\mathrm{~d} U_{N E}(0,0)$ & $\mathrm{d} U_{E}(0)$ & $\gamma_{E}^{P O}$ & $\mathrm{~d} U_{N E}(0,0)$ & $\mathrm{d} U_{E}(0)$ \\
2.80 & -25.00 & 8.93 & 3.97 & -20.98 & 5.28 & 4.89 & -12.61 & 2.58 \\
2.95 & -26.32 & 8.93 & 4.23 & -22.39 & 5.29 & 5.21 & -13.46 & 2.59 \\
3.11 & -27.78 & 8.93 & 4.53 & -24.01 & 5.30 & 5.57 & -14.43 & 2.59 \\
3.29 & -29.41 & 8.93 & 4.88 & -25.87 & 5.30 & 5.99 & -15.55 & 2.60 \\
3.50 & -31.25 & 8.93 & 5.28 & -28.06 & 5.31 & 6.48 & -16.87 & 2.61 \\
3.73 & -33.33 & 8.93 & 5.76 & -30.64 & 5.32 & 7.05 & -18.43 & 2.61 \\
4.00 & -35.71 & 8.93 & 6.32 & -33.74 & 5.34 & 7.74 & -20.30 & 2.62 \\
4.31 & -38.46 & 8.93 & 7.02 & -37.55 & 5.35 & 8.58 & -22.60 & 2.63 \\
4.67 & -41.67 & 8.93 & 7.89 & -42.32 & 5.37 & 9.62 & -25.49 & 2.65 \\
5.09 & -45.45 & 8.93 & 9.00 & -48.47 & 5.39 & 10.96 & -29.21 & 2.66 \\
5.60 & -50.00 & 8.93 & 10.48 & -56.71 & 5.41 & 12.74 & -34.21 & 2.68 \\
6.22 & -55.56 & 8.93 & 12.55 & -68.29 & 5.44 & 15.23 & -41.24 & 2.71 \\
7.00 & -62.50 & 8.93 & 15.64 & -85.76 & 5.48 & 18.94 & -51.89 & 2.74 \\
8.00 & -71.43 & 8.93 & 20.78 & -115.08 & 5.54 & 25.12 & -69.80 & 2.78 \\
9.33 & -83.33 & 8.93 & 31.05 & -174.19 & 5.61 & 37.43 & -106.08 & 2.83 \\
11.20 & -99.99 & 8.93 & 61.80 & -353.21 & 5.72 & 74.33 & -216.47 & 2.91
\end{tabular}

Note: Parameter values are: $\xi_{G}=10^{6}, \rho=0.04, \varepsilon_{L}=0.8, \alpha_{E}=0.1, \alpha_{K}=0.1, \alpha_{G}=0.5$. 
Table 1: The model in levels

$$
\begin{gathered}
\dot{C}(t)=[r(t)-\rho] C(t)-\lambda(\rho+\lambda)[K(t)+B(t)] \\
\dot{K}(t)=Y(t)-C(t)-G(t) \\
\dot{B}(t)=r(t) B(t)+G(t)-T(t) \\
\dot{E}(t)=f(E(t), K(t), G(t)) \\
Y(t)=\gamma_{0} K(t)^{1-\varepsilon_{L}} \\
W(t)=\varepsilon_{L} Y(t) \\
r(t)=\left(1-\varepsilon_{L}\right)\left(\frac{Y(t)}{K(t)}\right)
\end{gathered}
$$


Table 2: The log-linearised model ${ }^{\dagger}$

$$
\begin{gathered}
\dot{\tilde{C}}(t)=r \tilde{r}(t)+(r-\rho)\left[\tilde{C}(t)-\tilde{K}(t)-\left(1-\varepsilon_{L}\right)^{-1} \tilde{B}(t)\right] \\
\dot{\tilde{K}}(t)=\left(\frac{r}{1-\varepsilon_{L}}\right)\left[\tilde{Y}(t)-\omega_{C} \tilde{C}(t)-\tilde{G}(t)\right] \\
\tilde{B}(t)+\tilde{G}(t)=\tilde{T}(t)+r^{-1} \dot{\tilde{B}}(t) \\
\left(1 / \alpha_{E}\right) \dot{\tilde{E}}(t)=-\tilde{E}(t)-\alpha_{K} \tilde{K}(t)+\alpha_{G} \tilde{G}(t) \\
\tilde{Y}(t)=\left(1-\varepsilon_{L}\right) \tilde{K}(t) \\
\tilde{W}(t)=\tilde{Y}(t) \\
\tilde{r}(t)=-\varepsilon_{L} \tilde{K}(t)
\end{gathered}
$$

Shares and elasticities:

$\varepsilon_{L} \quad W L / Y=W / Y \quad$ Share of labour income in net output $\left(0<\varepsilon_{L}<1\right)$.

$\omega_{C} \quad C / Y$

$\alpha_{E} \quad-f_{E}$

Share of private consumption in net output $\left(0<\omega_{C}<1\right)$.

$\alpha_{K} \quad f_{K} K / f_{E} E$

Speed of regeneration of the environment $\left(\alpha_{E}>0\right)$.

$\alpha_{G} \quad-f_{G} Y l f_{E} E$

Elasticity of steady-state environmental quality with respect to the steadystate capital stock $\left(\alpha_{K}>0\right)$.

Elasticity of steady-state environmental quality with respect to steady-state public abatement $\left(\alpha_{G}>0\right)$.

$\dagger$ Initial debt is assumed to be zero $(B=0)$. 
Table 4. The efficiency and intergenerational distribution effects of public abatement

\begin{tabular}{|c|c|c|c|c|c|c|}
\hline & & $\lambda=0$ & $\lambda=0.01$ & $\lambda=0.02$ & $\lambda=0.06$ & $\lambda=0.10$ \\
\hline$\omega_{G}=0$ & $\begin{array}{l}\pi \\
\mathrm{d} U_{N E}(-\infty, 0) \\
\mathrm{d} U_{N E}(0,0) \\
\mathrm{d} U_{N E}(\infty, \infty) \\
\mathrm{d} \bar{U}_{N E}(0) \\
\mathrm{d} U_{E}(0) \\
\mathrm{d} U_{E}(\infty) \\
\sigma(\%)\end{array}$ & 10.71 & $\begin{array}{c}8.56 \\
0.51 \\
-25.12 \\
-25.22 \\
-20.22 \\
6.72 \\
10.13 \\
100.00\end{array}$ & $\begin{array}{c}7.07 \\
0.73 \\
-20.98 \\
-21.16 \\
-16.43 \\
5.28 \\
8.55 \\
100.00\end{array}$ & $\begin{array}{c}3.80 \\
0.77 \\
-12.61 \\
-12.88 \\
-9.26 \\
2.58 \\
5.31 \\
56.96\end{array}$ & $\begin{array}{r}2.22 \\
0.63 \\
-8.99 \\
-9.24 \\
-6.42 \\
1.55 \\
3.86 \\
39.00\end{array}$ \\
\hline$\omega_{G}=0.1$ & $\begin{array}{l}\pi \\
\mathrm{d} U_{N E}(-\infty, 0) \\
\mathrm{d} U_{N E}(0,0) \\
\mathrm{d} U_{N E}(\infty, \infty) \\
\mathrm{d} \bar{U}_{N E}(0) \\
\mathrm{d} U_{E}(0) \\
\mathrm{d} U_{E}(\infty) \\
\sigma(\%)\end{array}$ & 7.93 & $\begin{array}{c}6.26 \\
0.61 \\
-28.73 \\
-28.88 \\
-22.66 \\
6.73 \\
10.16 \\
78.20\end{array}$ & $\begin{array}{r}5.07 \\
0.86 \\
-24.01 \\
-24.27 \\
-18.40 \\
5.30 \\
8.60 \\
66.10\end{array}$ & $\begin{array}{r}2.39 \\
0.90 \\
-14.43 \\
-14.80 \\
-10.37 \\
2.59 \\
5.36 \\
42.53\end{array}$ & $\begin{array}{c}1.09 \\
0.73 \\
-10.29 \\
-10.63 \\
-7.19 \\
1.55 \\
3.90 \\
30.90\end{array}$ \\
\hline$\omega_{G}=0.2$ & $\begin{array}{l}\pi \\
\mathrm{d} U_{N E}(-\infty, 0) \\
\mathrm{d} U_{N E}(0,0) \\
\mathrm{d} U_{N E}(\infty, \infty) \\
\mathrm{d} \bar{U}_{N E}(0) \\
\mathrm{d} U_{E}(0) \\
\mathrm{d} U_{E}(\infty) \\
\sigma(\%)\end{array}$ & 4.46 & $\begin{array}{c}3.38 \\
0.74 \\
-33.56 \\
-33.79 \\
-25.82 \\
6.74 \\
10.20 \\
48.01\end{array}$ & $\begin{array}{c}2.58 \\
1.04 \\
-28.06 \\
-28.44 \\
-20.96 \\
5.31 \\
8.65 \\
43.82\end{array}$ & $\begin{array}{c}0.68 \\
1.07 \\
-16.87 \\
-17.40 \\
-11.81 \\
2.61 \\
5.43 \\
32.20\end{array}$ & $\begin{array}{r}-0.24 \\
0.87 \\
-12.04 \\
-12.51 \\
-8.19 \\
1.57 \\
3.96 \\
24.72\end{array}$ \\
\hline$\omega_{G}=0.3$ & $\begin{array}{l}\pi \\
\mathrm{d} U_{N E}(-\infty, 0) \\
\mathrm{d} U_{N E}(0,0) \\
\mathrm{d} U_{N E}(\infty, \infty) \\
\mathrm{d} \bar{U}_{N E}(0) \\
\mathrm{d} U_{E}(0) \\
\mathrm{d} U_{E}(\infty) \\
\sigma(\%)\end{array}$ & 0 & $\begin{array}{c}-0.30 \\
0.93 \\
-40.33 \\
-40.71 \\
-30.10 \\
6.76 \\
10.25 \\
30.72\end{array}$ & $\begin{array}{c}-0.60 \\
1.28 \\
-33.74 \\
-34.35 \\
-24.42 \\
5.34 \\
8.74 \\
29.97\end{array}$ & $\begin{array}{r}-1.46 \\
1.30 \\
-20.30 \\
-21.10 \\
-13.77 \\
2.62 \\
5.52 \\
24.73\end{array}$ & $\begin{array}{c}-1.87 \\
1.06 \\
-14.49 \\
-15.20 \\
-9.56 \\
1.58 \\
4.03 \\
19.97\end{array}$ \\
\hline$\omega_{G}=0.4$ & $\begin{array}{l}\pi \\
\mathrm{d} U_{N E}(-\infty, 0) \\
\mathrm{d} U_{N E}(0,0) \\
\mathrm{d} U_{N E}(\infty, \infty) \\
\mathrm{d} \bar{U}_{N E}(0) \\
\mathrm{d} U_{E}(0) \\
\mathrm{d} U_{E}(\infty) \\
\sigma(\%)\end{array}$ & -5.96 & $\begin{array}{c}-5.21 \\
1.19 \\
-50.53 \\
-51.18 \\
-36.28 \\
6.78 \\
10.34 \\
20.51\end{array}$ & $\begin{array}{r}-4.82 \\
1.63 \\
-42.32 \\
-43.34 \\
-29.45 \\
5.37 \\
8.85 \\
21.15\end{array}$ & $\begin{array}{c}-4.23 \\
1.64 \\
-25.49 \\
-26.79 \\
-16.65 \\
2.65 \\
5.65 \\
19.24\end{array}$ & $\begin{array}{r}-3.94 \\
1.33 \\
-18.19 \\
-19.34 \\
-11.58 \\
1.59 \\
4.14 \\
16.29\end{array}$ \\
\hline \multicolumn{2}{|l|}{$\begin{array}{l}\hat{\omega}_{G} \\
\omega_{G}^{M R} \\
\omega_{G}^{P I}\end{array}$} & $\begin{array}{l}0.300 \\
0.300 \\
0.300\end{array}$ & $\begin{array}{l}0.293 \\
0.191 \\
0.250\end{array}$ & $\begin{array}{l}0.283 \\
0.167 \\
0.200\end{array}$ & $\begin{array}{l}0.234 \\
0.044 \\
0.000\end{array}$ & $\begin{array}{l}0.183 \\
0.000 \\
0.000\end{array}$ \\
\hline
\end{tabular}

Note: Parameter values are $\rho=0.04, \varepsilon_{L}=0.80, \alpha_{E}=0.1, \alpha_{K}=0.1, \alpha_{G}=0.5, \gamma_{E}=0.10$ and $\xi_{G}=10^{6} . \mathrm{d} \bar{U}_{N E}(0) \equiv$ $\int_{-\infty}^{0} \lambda \mathrm{e}^{\lambda v} \mathrm{~d} U_{N E}(v, 0) \mathrm{d} v$ is the aggregate non-environmental welfare change of existing generations. $\hat{\omega}_{G}$ is the optimal (egalitarian) abatement share (see sections 3.4 and 4.2), i.e. the maximum abatement share at which all generations are just indifferent about a marginal increase in abatement if public debt policy ensures that all generations experience the same change in overall welfare. $\omega_{G}^{M R}$ is the maximum abatement share under majority rule, i.e. $\omega_{G}$ such that $\sigma(\%)=50$ (see section 3.6). $\omega_{G}^{P I}$ is the Pareto-improving abatement share if debt policy ensures only that all current generations enjoy the same welfare (see section 4.1). 


\section{Footnotes}

1. For the importance of intergenerational distributional issues within the context of environmental policy, see Norgaard (1993) and Pasek (1992).

2. Without explicitly distinguishing overlapping generations, Becker (1982) explores an intergenerationally equitable program with the aid of a Rawlsian maximin criterion. This implies that utility enjoyed at each point in time is constant across time.

3. Our paper is thus related to the literature on the macroeconomic effects of public investment (see, e.g., Turnovsky and Fisher (1995), Fisher and Turnovsky (1998), and Gramlich (1994)). For the impact of public spending within the context of overlappinggenerations models, see Auerbach and Kotlikoff (1987), Marini and van der Ploeg (1988), and Romer (1988).

4. Wages and lump-sum taxes do not feature a generation index because they are independent of age.

5. We use the term net production because production is measured after allowing for depreciation of the capital stock.

6. Ignoring time indexes, gross operating surplus equals $\tilde{F}(K, L)-W L$ where $\tilde{F}(K, L)=F(K, L)+\delta_{K} K$ stands for gross production. Since bonds and equity are perfect substitutes, arbitrage ensures that $\dot{V}=r V-\left[F(K, L)-W L+\delta_{K} K-I\right]$. Integrating this expression subject to a transversality condition, we arrive at the maximand (2.6) in the text.

7. In view of the linear homogeneity of the production function and the marginal productivity conditions (2.7), the value of the firm can be written as:

$$
V(t) \equiv \int_{t}^{\infty}[r(\tau) K(\tau)-\dot{K}(\tau)] \exp \left(-\int_{t}^{\tau} r(\mu) \mathrm{d} \mu\right) \mathrm{d} \tau=K(t) .
$$

8. It is assumed that $f_{G}>0>f_{G G}$. This, together with the consumption smoothing desire of households, ensures a once-off massive clean-up of the environment is neither feasible nor desirable. Since growth is absent in the model, the formulation employed here implies a well-defined steady state even in the absence of public abatement.

9. The Euler equation is obtained by combining (2.3) and (2.5) with the dynamic version of (2.4) and noting that $A(t) \equiv K(t)+B(t)$.

10. The remainder of this paper (including Table 2) assumes that public debt is zero in the initial steady state, i.e., $B=0$.

11. The reader is referred to Bovenberg and Heijdra (1998), which is available on request, for a description of the solution methods and all mathematical derivations.

12. Saddle-point stability ensures that the denominator of this expression is positive.

13. Such a shock is defined as the arrival of news concerning the instantaneous introduction of the policy at some time in the future (i.e. a step function).

14. The first derivative of a multiple adjustment term with respect to time is zero at the time of the policy shock (See Lemma A.3 in Bovenberg and Heijdra (1998)). 
15. Both these abatement shares are based on an equilibrium without crowding out of capital. Crowding out is absent in (3.12) because a representative, infinitely-lived agent internalizes all effects on non-environmental welfare. In (4.3), public debt policy eliminates all distributional effects in terms of non-environmental welfare.

16. This egalitarian policy approach is similar to the one adopted by Auerbach and Kotlikoff (1987, p. 56). They use the construct of a Lump Sum Redistribution Agency to compute efficiency gains.

17. This assumes that $\alpha_{K}$ is not too large. If this parameter is too large, public debt policy can not ensure that the overall welfare gains are distributed equally among the various generations. The reason is that the redistribution of non-environmental gains in favour of current generations imply crowding-out of capital. If this crowding-out of polluting capital produces especially large gains in environmental welfare, the environmental gains in favour of future generations dominate the non-environmental losses so that future generations gain rather than lose on account of a larger stock of public debt. 


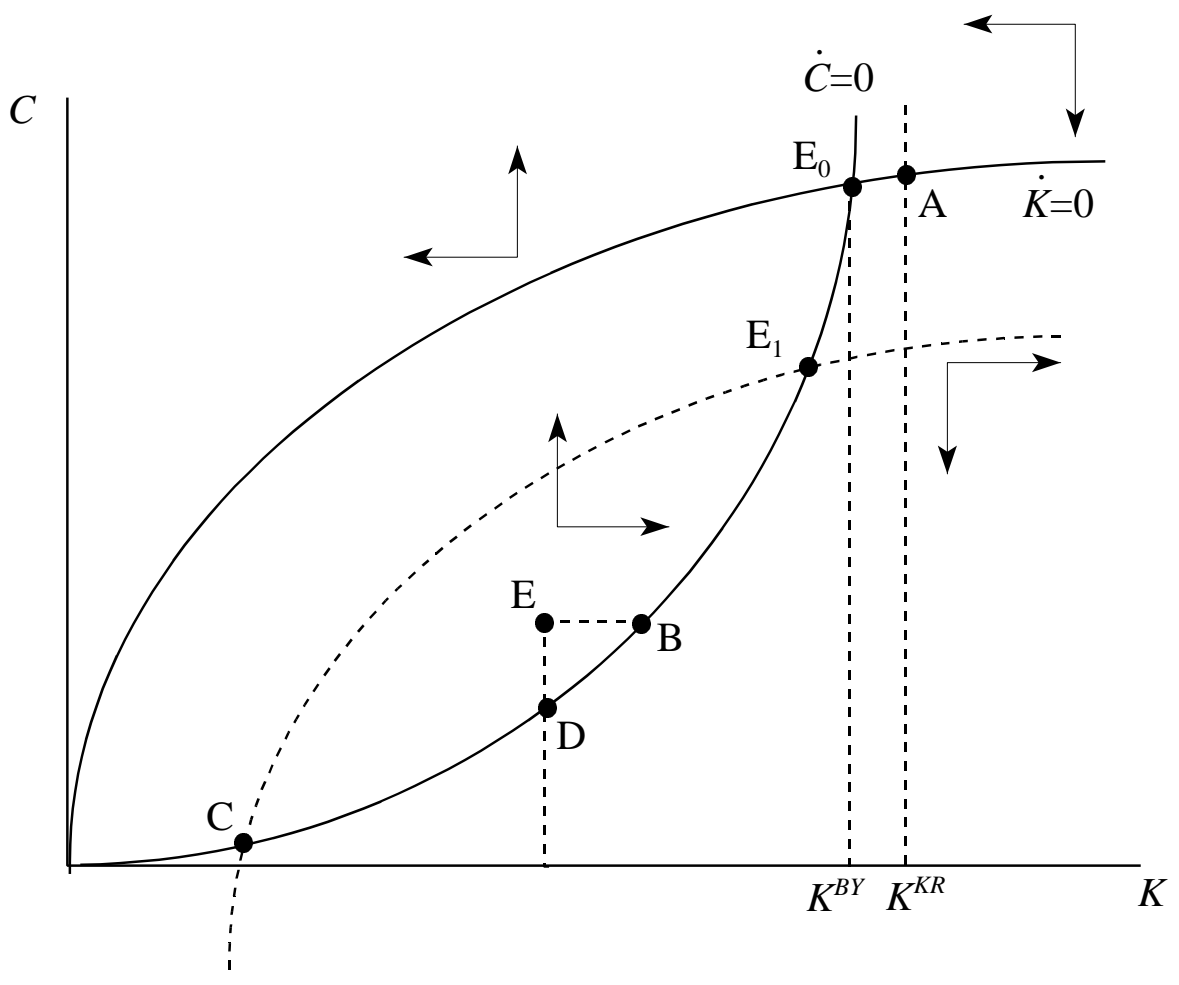

Figure 1. Equilibrium and stability.

Key: $K^{K R}$ is the Keynes-Ramsey capital stock, for which $r=\partial \mathrm{F} / \partial K=\rho . K^{B Y}$ is the BlanchardYaari equilibrium capital stock. 


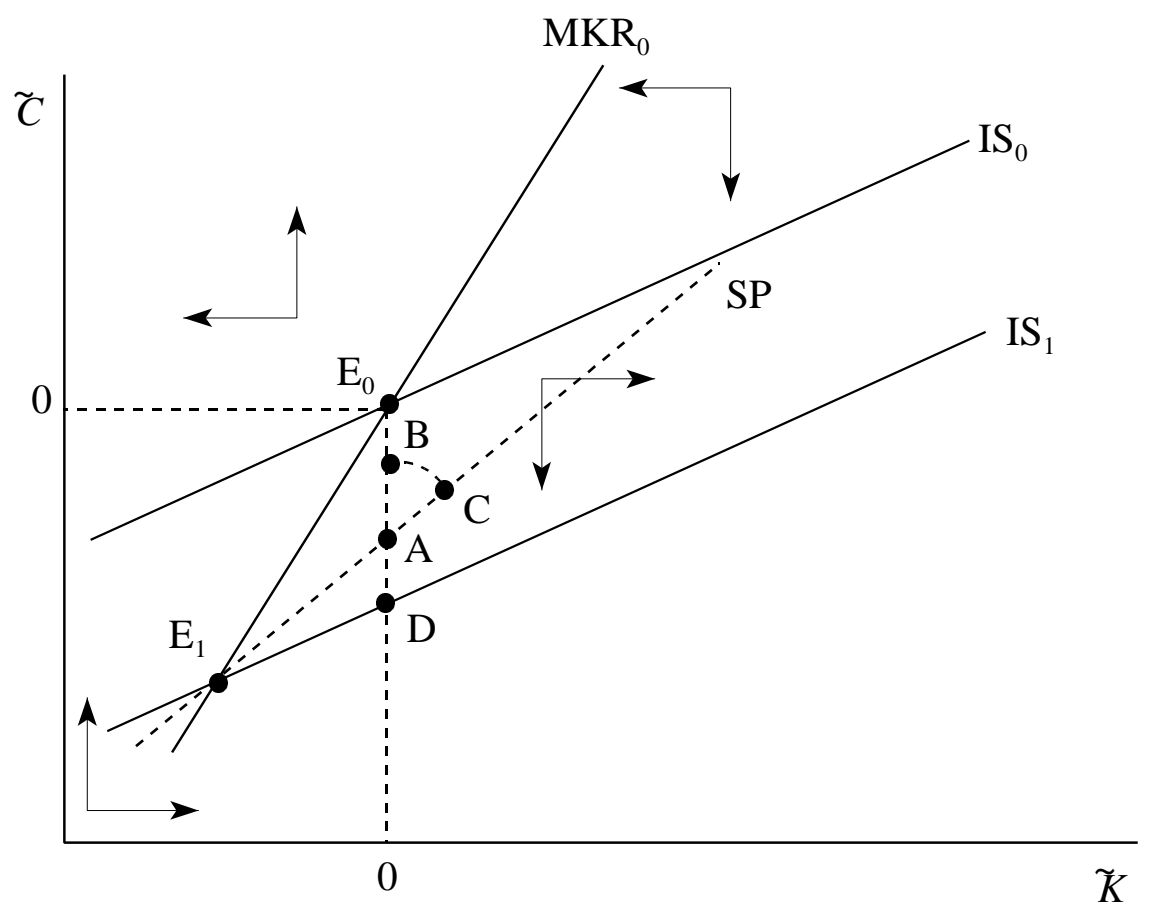

Figure 2. Macroeconomic effects of public abatement.

Key: Public abatement shifts the IS curve from $\mathrm{IS}_{0}$ to $\mathrm{IS}_{1}$ and the steady state moves from $\mathrm{E}_{0}$ to $\mathrm{E}_{1}$. If the policy is introduced abruptly, the transition path consists of a discrete adjustment from $\mathrm{E}_{0}$ to $\mathrm{A}$ at the time of the shock, followed by gradual adjustment along the saddle path SP from $A$ to $E_{1}$. With a gradual introduction $\left(\xi_{G} \rightarrow \infty\right)$, the adjustment path involves a discrete jump from $\mathrm{E}_{0}$ to $\mathrm{B}$ at the time of the shock, followed by gradual adjustment along the dashed trajectory from $\mathrm{B}$ to $\mathrm{E}_{1}$. 
Figure A.1. Adjustment and transition terms

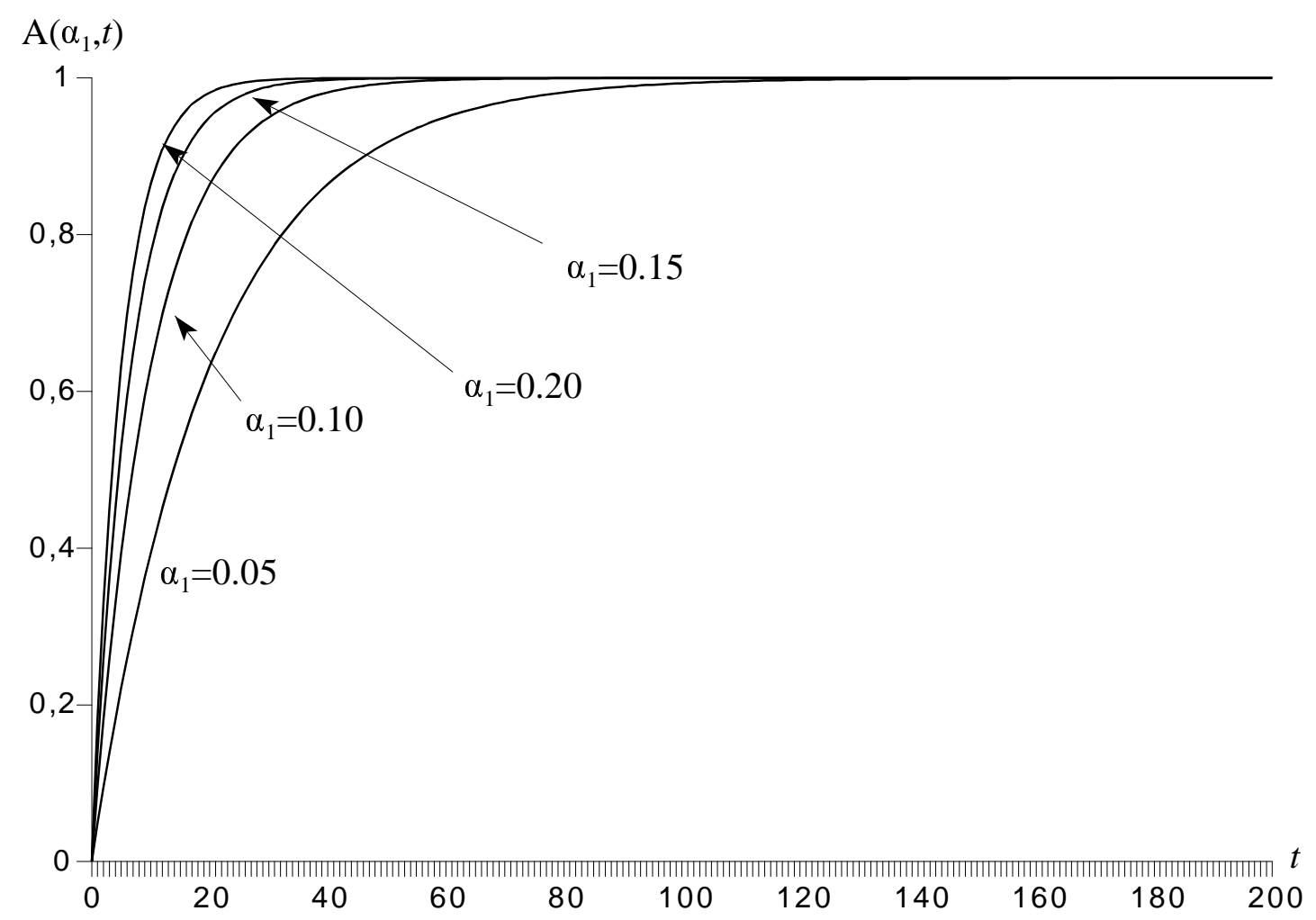

Key: The single adjustment term $\mathrm{A}\left(\alpha_{1}, t\right)$ is increasing over time. As $\alpha_{1}$ rises, the closer $\mathrm{A}\left(\alpha_{1}, t\right)$ approximates a step function.

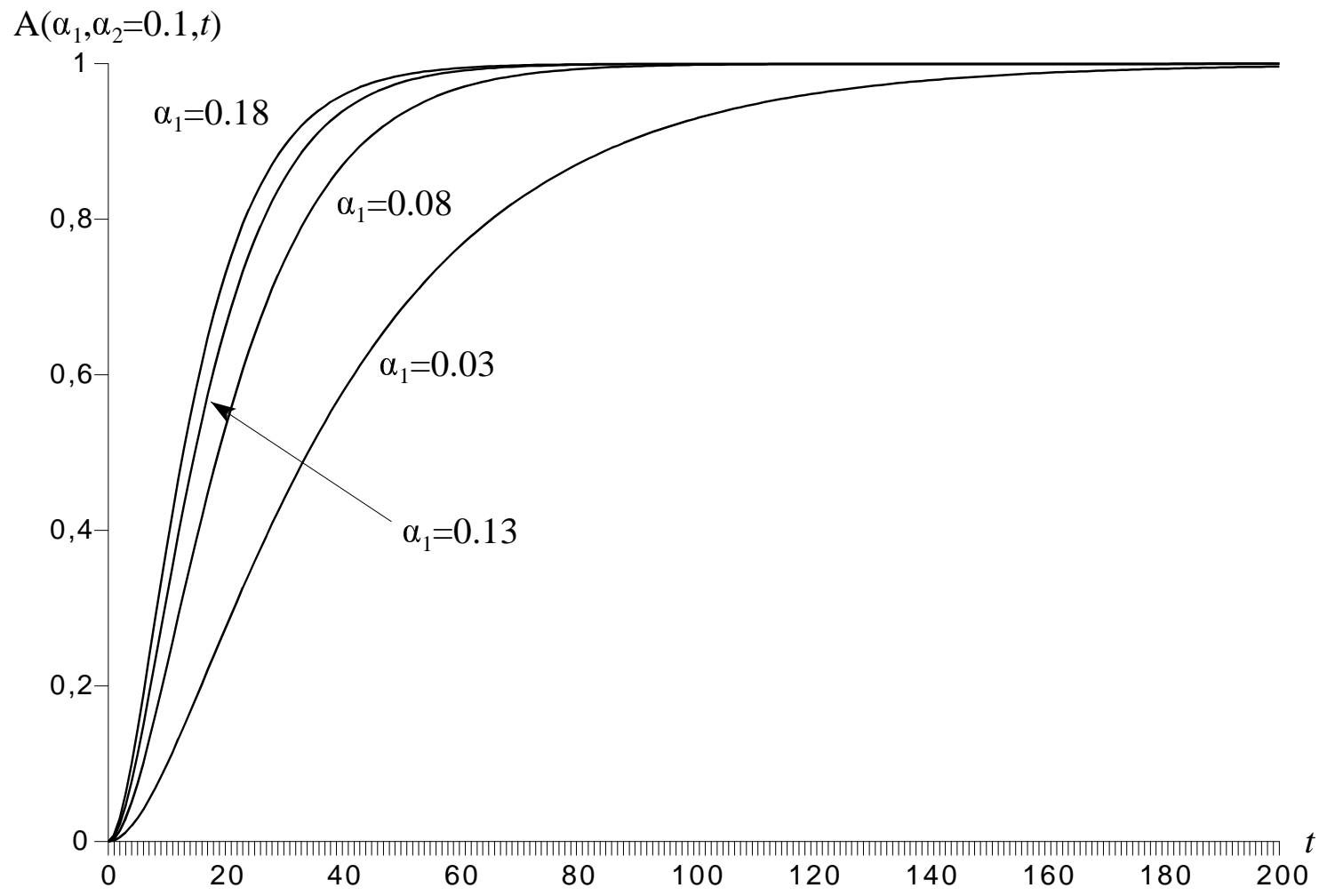

Key: The multiple adjustment term $\mathrm{A}\left(\alpha_{1}, \alpha_{2}, t\right)$ is $\mathrm{S}$-shaped and increasing over time. As $\alpha_{1}$ rises (for a given value of $\alpha_{2}$ ), $\mathrm{A}\left(\alpha_{1}, \alpha_{2}, t\right)$ more and more approximates a step function. 
Figure A.2. The effect of the speed of introduction on the quality of the environment

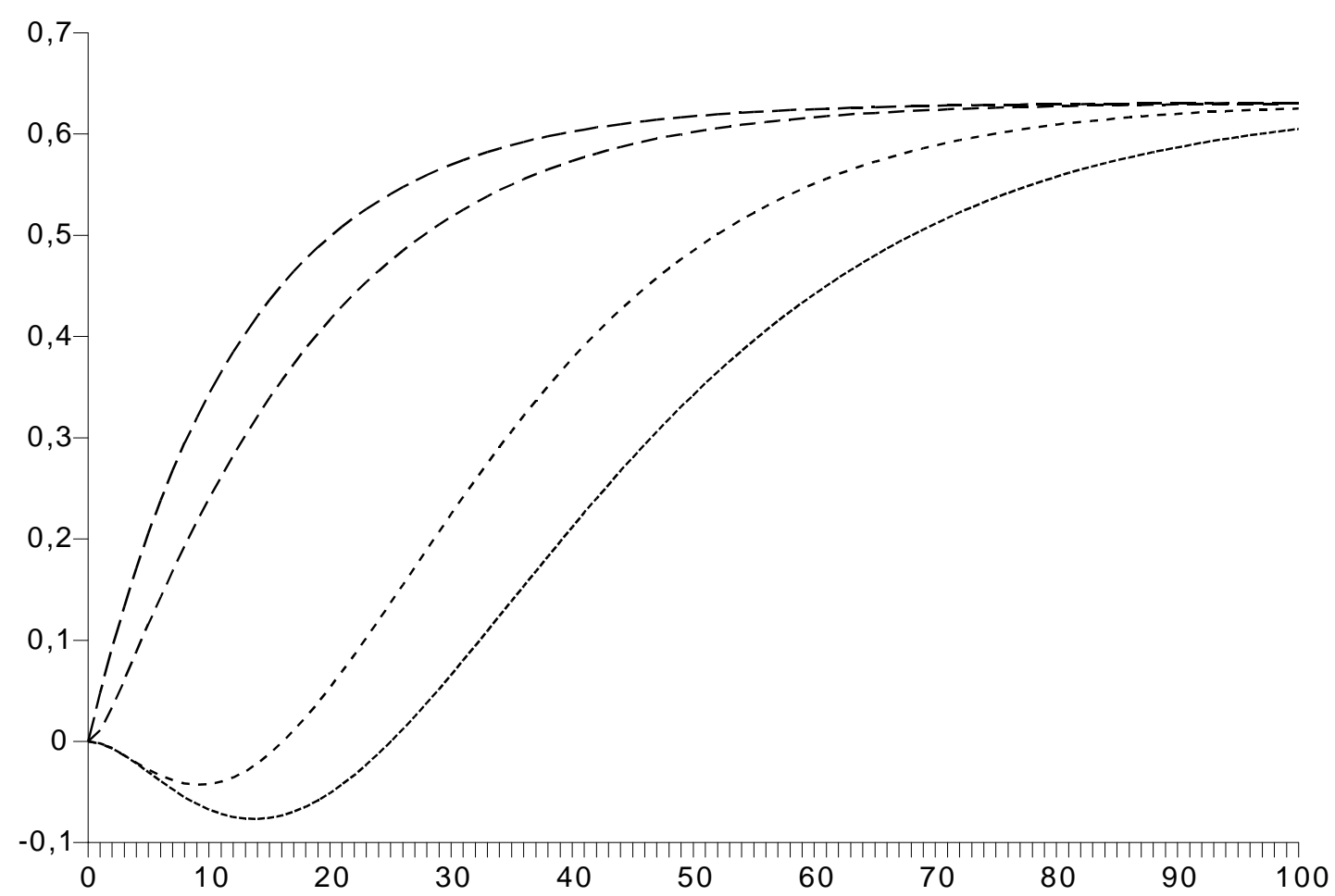

Key: The tax rate on capital is $t_{K}=0, v$ is the generations index for existing generations, and $t$ is the index for historical time, which also represents the generations index for future generations whose welfare is evaluated at birth. 
Figure 3.a. The effect of the speed of introduction on the welfare paths

Private welfare: $\mathrm{d} U_{N E}$

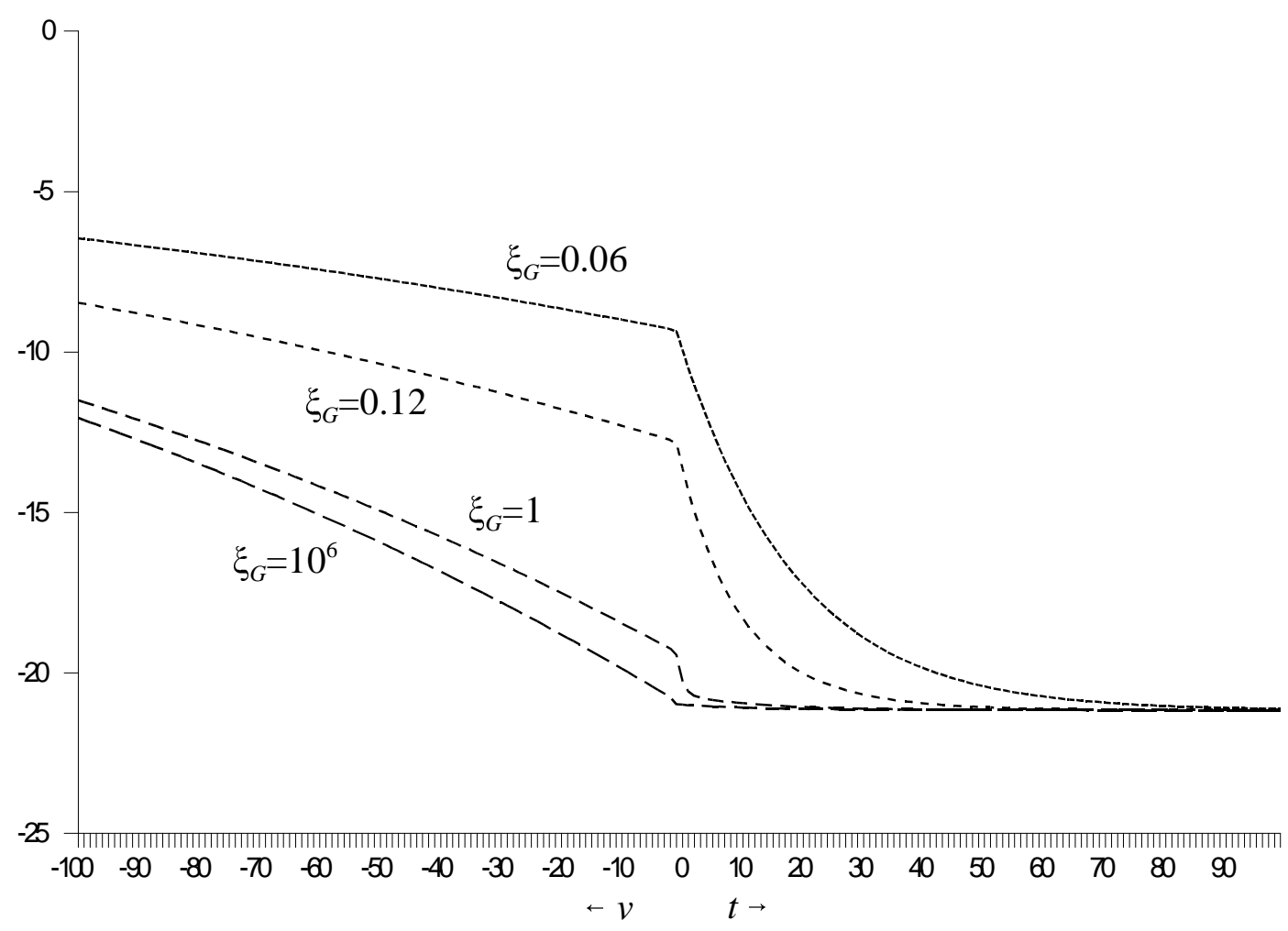

Environmental welfare: $\mathrm{d} U_{E}$

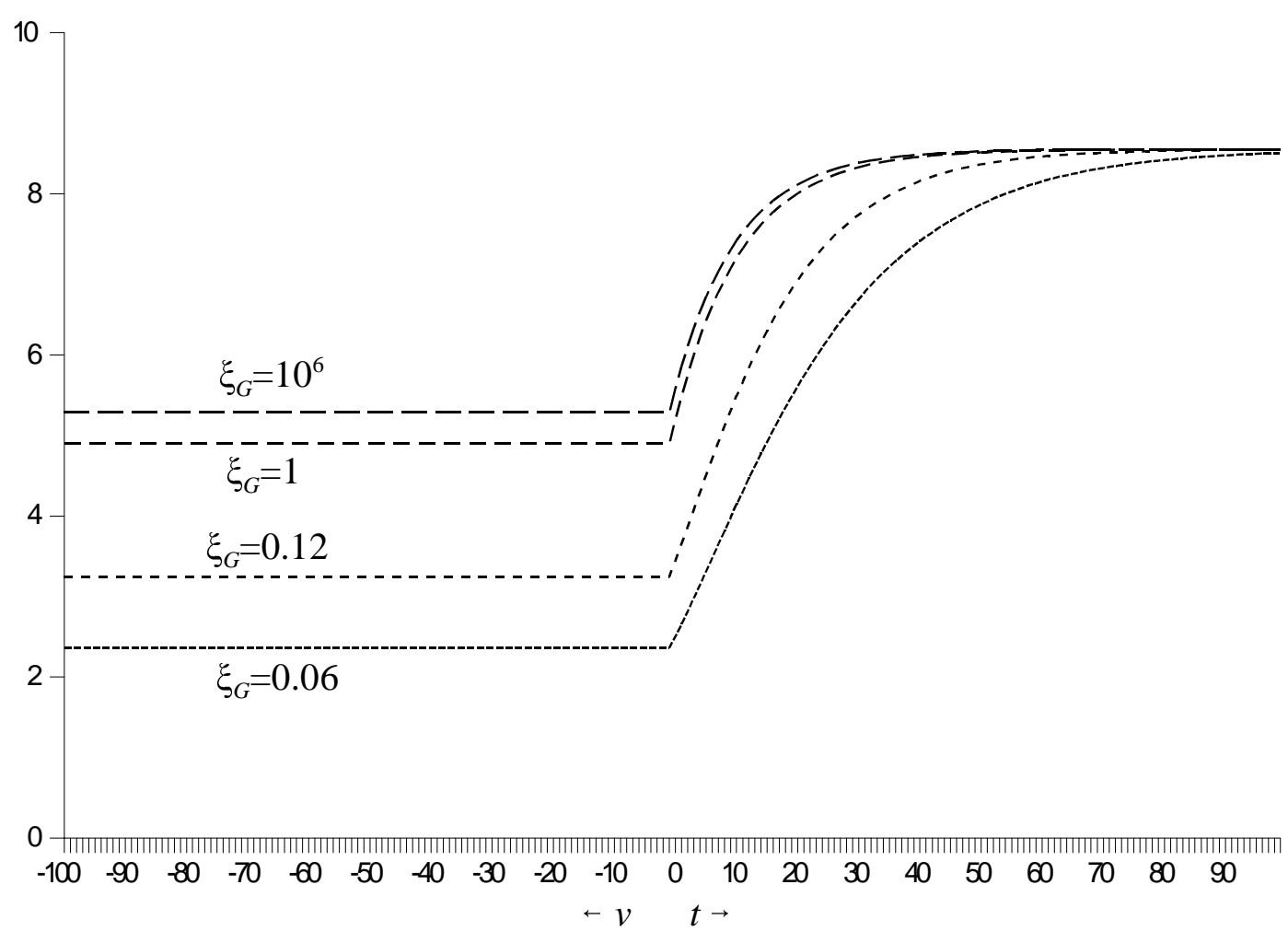

Key: The parameters are: $\xi_{G}=$ variable, $\lambda=0.02, \omega_{G}=0, \varepsilon_{L}=0.8, \rho=0.04, \alpha_{E}=0.1, \alpha_{K}=0.1, \alpha_{G}$ $=0.5$. $v$ represents the generations index for current generations, and $t$ is the index for historical time, which represents the generations index for future generations whose welfare is evaluated at birth. 
Figure 3.b. The effect of the initial share of abatement on the welfare paths

Private welfare: $\mathrm{d} U_{N E}$

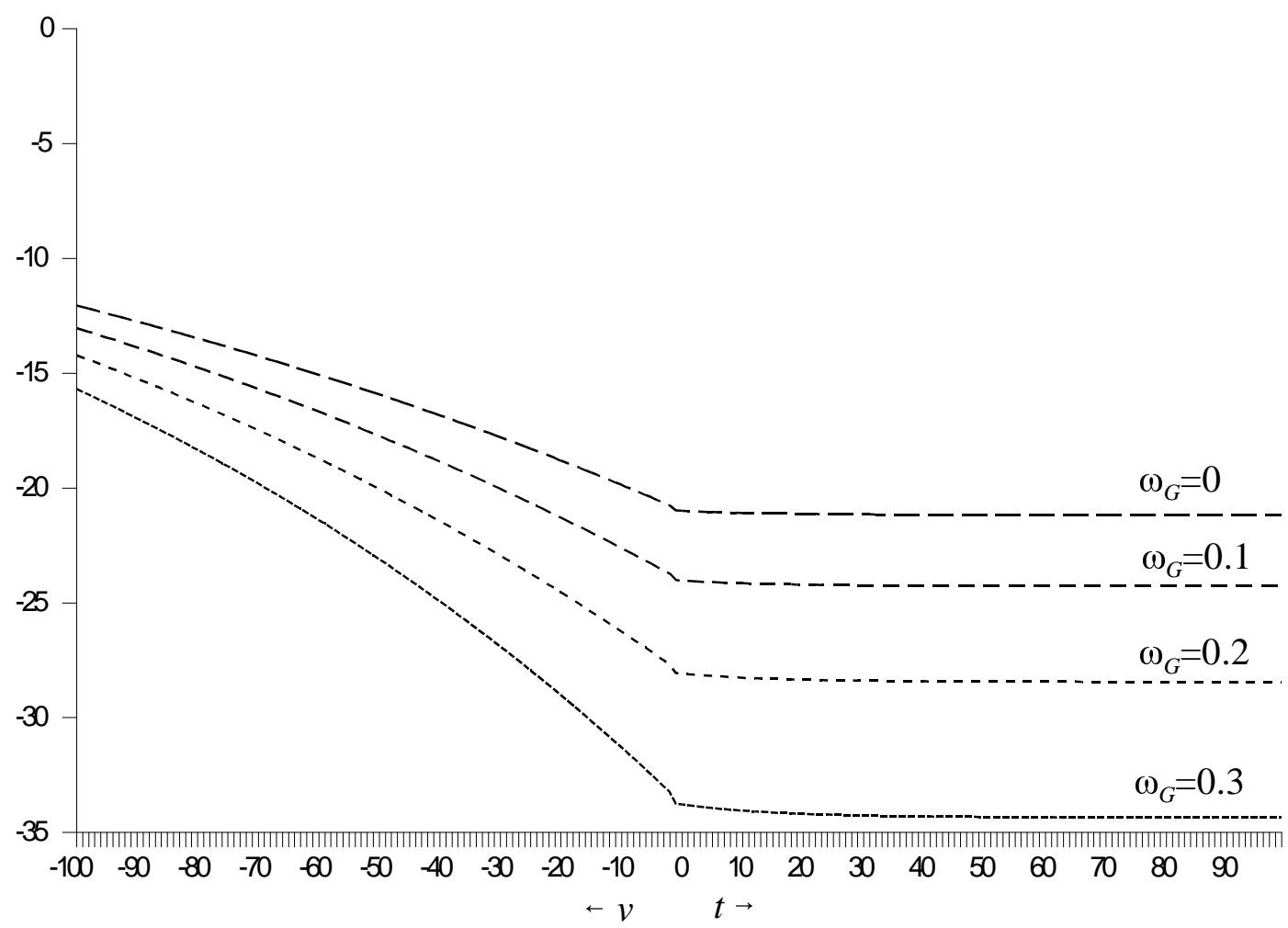

Environmental welfare: $\mathrm{d} U_{E}$

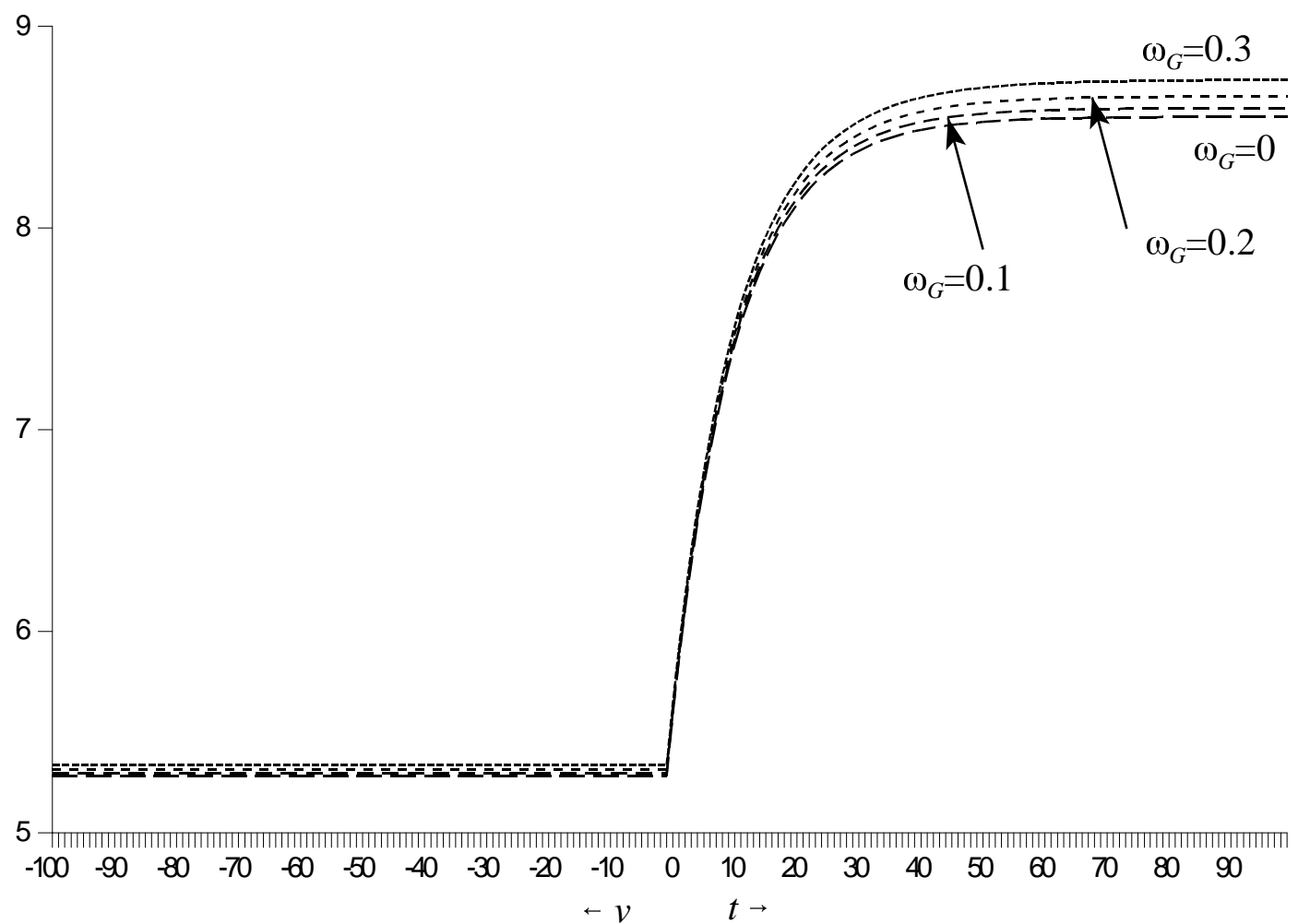

Key: The parameters are: $\omega_{G}=$ variable, $\lambda=0.02, \xi_{G}=10^{6}, \varepsilon_{L}=0.8, \rho=0.04, \alpha_{E}=0.1, \alpha_{K}=0.1$, $\alpha_{G}=0.5$. $v$ represents the generations index for current generations, and $t$ is the index for historical time, which represents the generations index for future generations whose welfare is evaluated at birth. 
Figure 3.c. The effect of the birth rate on the welfare paths

Private welfare: $\mathrm{d} U_{N E}$

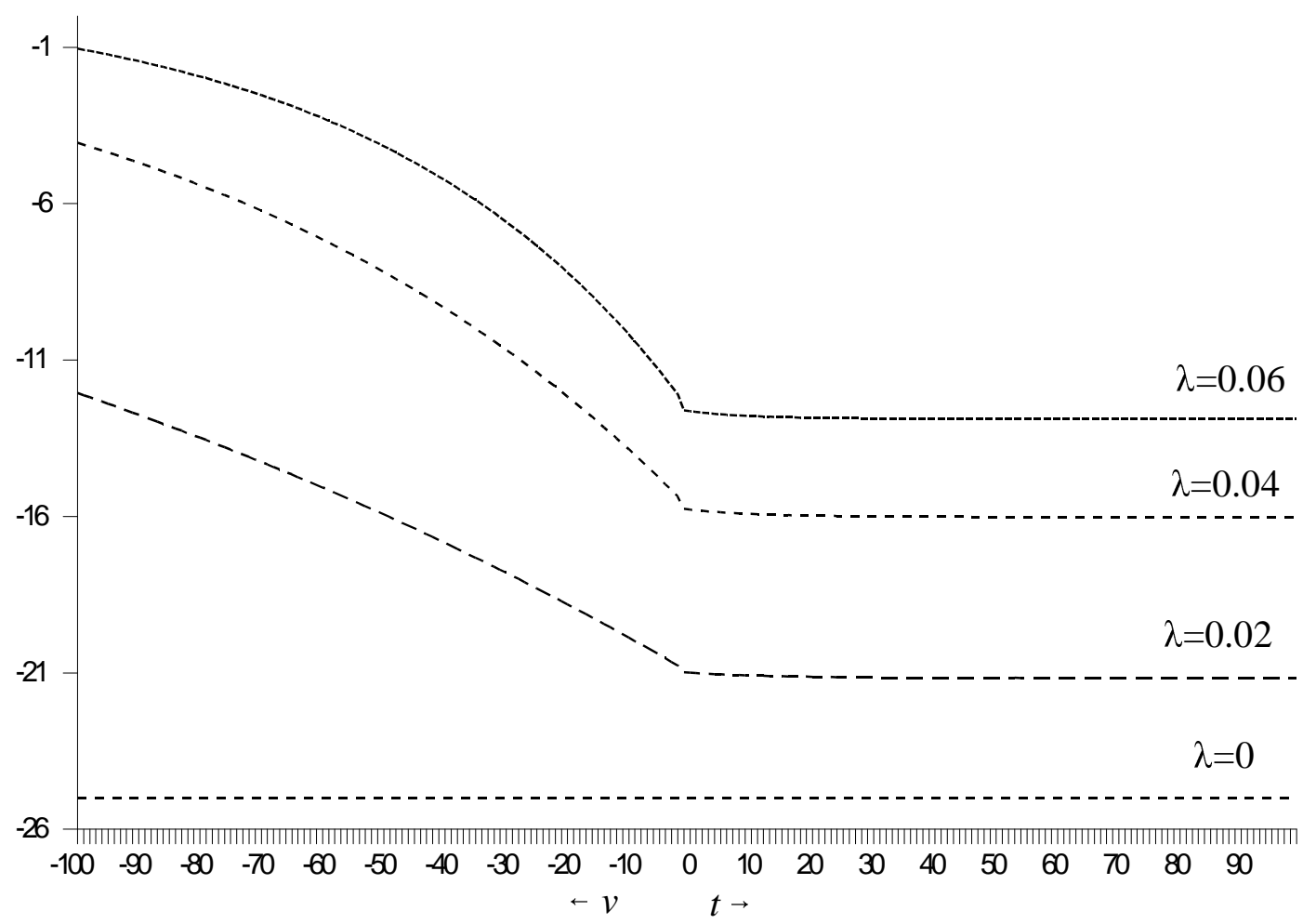

Environmental welfare: $\mathrm{d} U_{E}$

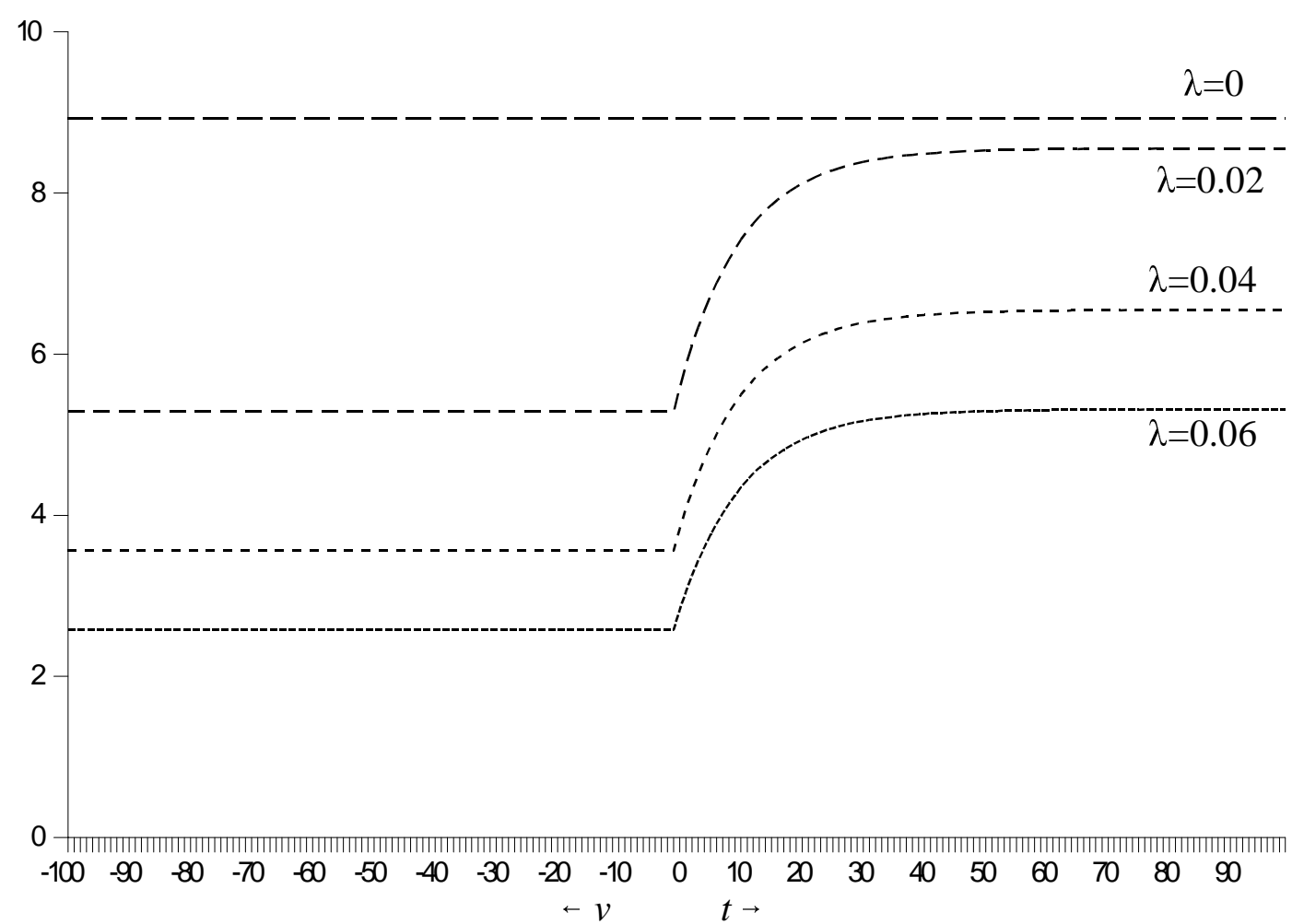

Key: The parameters are: $\lambda=$ variable, $\omega_{G}=0, \xi_{G}=10^{6}, \varepsilon_{L}=0.8, \rho=0.04, \alpha_{E}=0.1, \alpha_{K}=0.1, \alpha_{G}=0.5$. $v$ represents the generations index for current generations, and $t$ is the index for historical time, which represents the generations index for future generations whose welfare is evaluated at birth. 
Figure 4.a. Required environmental weights and policy speed

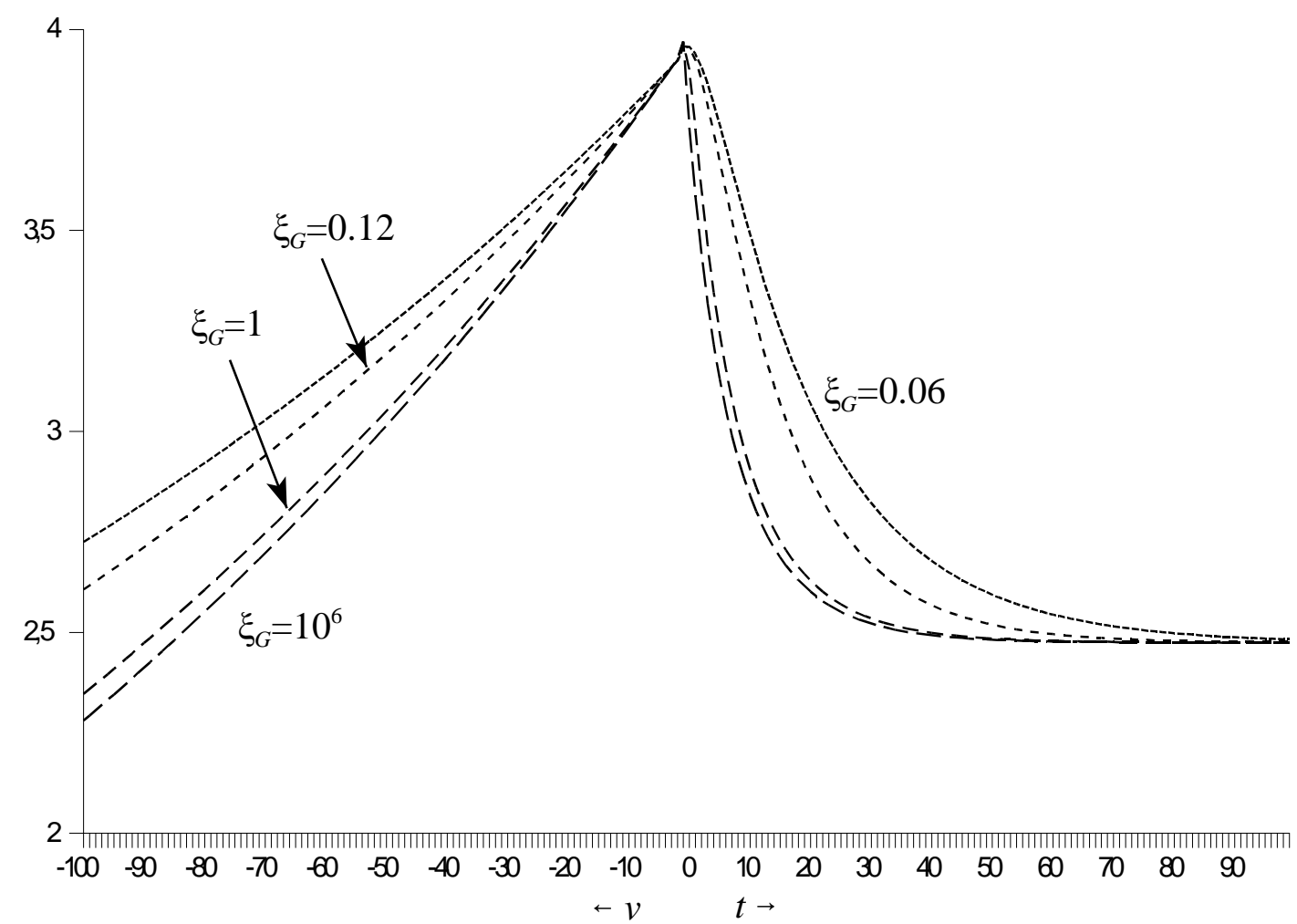

Figure 4.b. Required environmental weights and initial abatement share

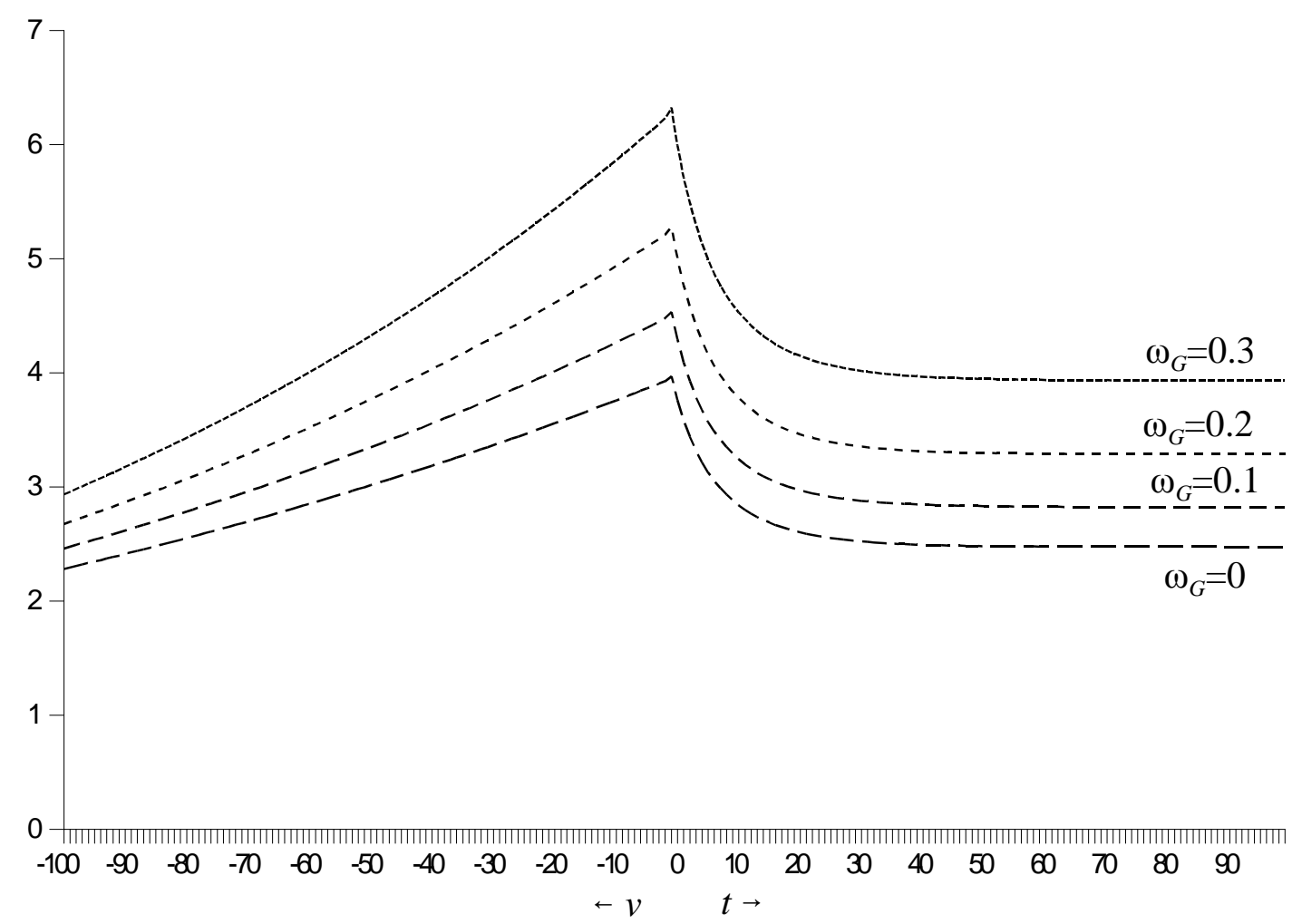


Figure 4.c. Required environmental weights and birth rate

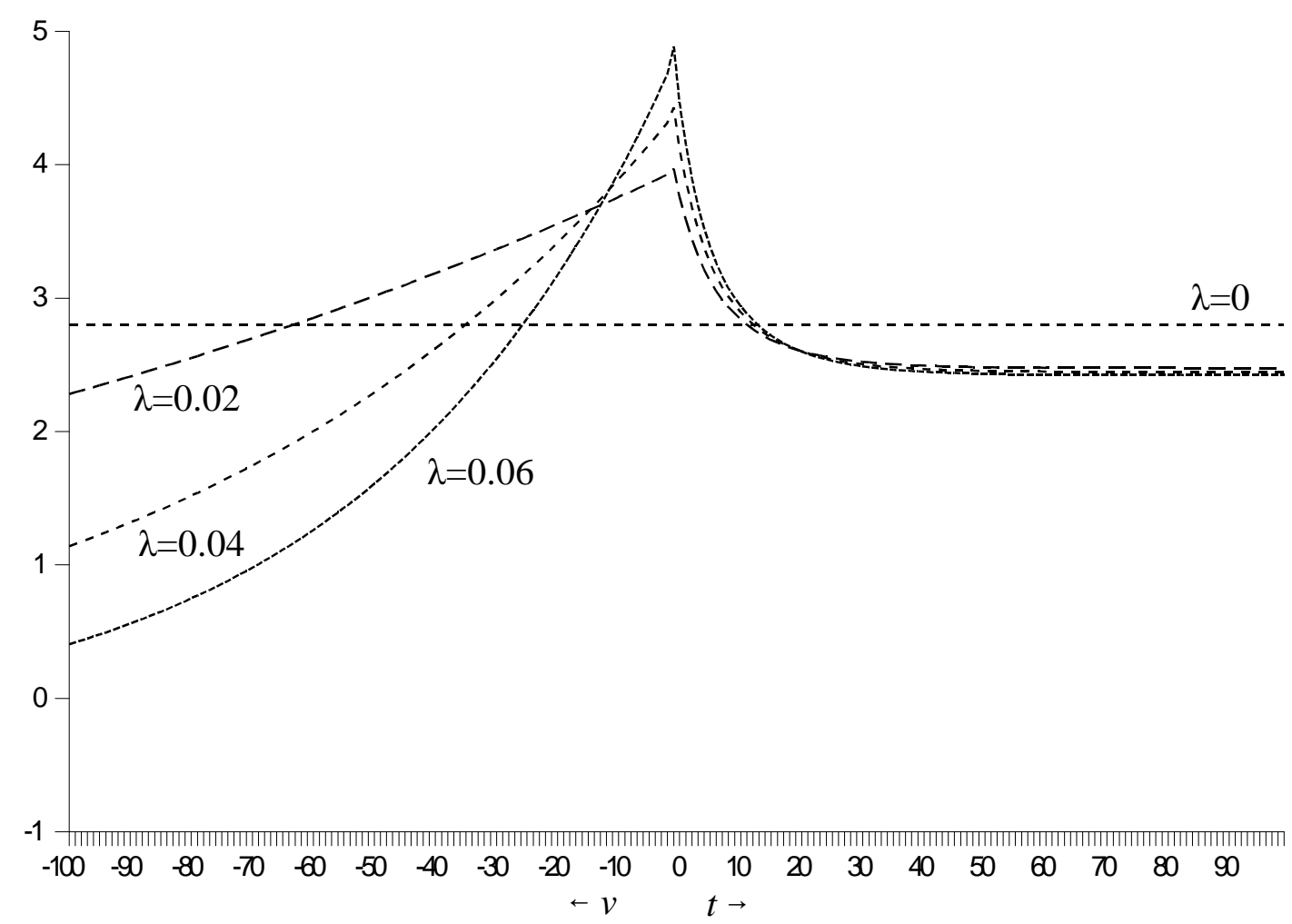

Key: Environmental weights $\gamma_{E}\left(v, v^{\prime}\right)$ are such that each generation is indifferent to a marginal increase in public abatement. The common parameters in panels (a)-(c) are: $\varepsilon_{L}=0.8, \rho=0.04$, $\alpha_{E}=0.1, \alpha_{K}=0.1, \alpha_{G}=0.5$. In panel (a), $\xi_{G}=$ variable, $\lambda=0.02, \omega_{G}=0$; in panel (b), $\omega_{G}=$ variable, $\lambda=0.02, \xi_{G}=10^{6}$; in panel (c), $\lambda=$ variable, $\omega_{G}=0, \xi_{G}=10^{6}$; 